Utah State University

DigitalCommons@USU

7-10-2020

\title{
Towards More Realistic Estimates of DOM Decay in Streams: Incubation Methods, Light, and Non-Additive Effects
}

Julia E. Kelso

Utah State University

Emma J. Rosi

Cary Institute of Ecosystem Studies

Michelle A. Baker

Utah State University

Follow this and additional works at: https://digitalcommons.usu.edu/eco_pubs

Part of the Ecology and Evolutionary Biology Commons

\section{Recommended Citation}

Kelso, Julia, Rosi, Emma, Baker, Michelle. "Towards More Realistic Estimates of DOM Decay in Streams: Incubation Methods, Light, and Non-Additive Effects." Freshwater Science,vol. 39, no. 3, 2020, pp.

559-575. https://doi.org/10.1086/710218

This Article is brought to you for free and open access by the Ecology Center at DigitalCommons@USU. It has been accepted for inclusion in Ecology Center Publications by an authorized administrator of DigitalCommons@USU.

For more information, please contact

digitalcommons@usu.edu.

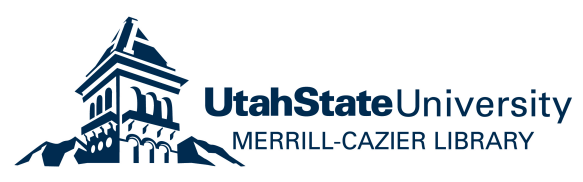




\title{
Towards more realistic estimates of DOM decay in streams: Incubation methods, light, and non-additive effects
}

\author{
Julia E. Kelso ${ }^{1,3}$, Emma J. Rosi ${ }^{2,4}$, and Michelle A. Baker ${ }^{1,5}$ \\ ${ }^{1}$ Department of Biology and the Ecology Center, Utah State University, 5305 Old Main Hill, Logan, Utah 84322 USA \\ ${ }^{2}$ Cary Institute of Ecosystem Studies, 2801 Sharon Turnpike, Millbrook, New York 12545 USA
}

\begin{abstract}
Dissolved organic matter (DOM) is the largest pool of organic matter in aquatic ecosystems and is a primary substrate for microbial respiration in streams. However, understanding the controls on DOM processing by microbes remains limited, and DOM decay rates remain largely unconstrained. Many DOM decay rates are quantified with bioassays in dark bottles, which may underestimate DOM decay in streams because these bioassays do not include a benthic zone and do not account for abiotic factors of DOM loss, such as photodegradation and volatilization. We measured decay of labile and semi-labile DOM over $3 \mathrm{~d}$ in experimental streams and bottle bioassays. Incubations included 3 types of labile DOM (algal, light-degraded soil, and light-degraded plant leachates) and 2 types of semi-labile DOM (plant and soil leachates). We also quantified decay rates when labile and semi-labile DOM were mixed to test for non-additive effects, or priming, of semi-labile DOM by labile DOM. We converted dissolved organic carbon (DOC) decay rates to half-lives and uptake velocities and compared these metrics to previous studies that quantified DOC loss in bioassays or real streams. Percent DOC lost over time, or biodegradable DOC, was greater in experimental streams than in bioassays. DOC decay rates and uptake velocities did not differ between bioassays and experimental streams but were lower than in real streams. Mixing of labile and semi-labile DOM resulted in both positive and negative non-additive effects. Consistent non-additive effects were difficult to quantify because decay rates were not constant over the course of each incubation, as shown by faster decay rates calculated over the first $6 \mathrm{~h}$ of incubation compared to $>70 \mathrm{~h}$. Decay rates of leachates from natural substrates (e.g., algae and soil) incubated over short periods of time (hours-days) are needed for models that aim to quantify organic matter transformation in aquatic ecosystems with short residence times, such as rivers and streams.
\end{abstract}

Key words: priming, dissolved organic matter, bioassay, dark bottle, $1^{\text {st }}$-order decay, biexponential decay, uptake velocity, fluorescence

Dissolved organic matter (DOM) is the largest pool of organic matter $(\mathrm{OM})$ in aquatic ecosystems (Webster and Meyer 1997, Wetzel 2001), and the flux of DOM from terrestrial ecosystems to inland waters has been recognized as an important component of organic carbon budgets from watershed (Moody et al. 2013) to global scales (Hotchkiss et al. 2015, Butman et al. 2016, Drake et al. 2018). Recent estimates of stream and river (hereafter stream) OM transformation, transport, and storage indicate that streams mineralize a large proportion of terrestrial net ecosystem production at continental and global scales (Hotchkiss et al. 2015, Butman et al. 2016, Drake et al. 2018). However, reach-scale measures of DOM removal, such as dissolved organic carbon (DOC) decay and uptake velocity, span 10 orders of magnitude (Cory and Kaplan 2012, Mineau et al. 2016, Seybold and McGlynn 2018). Thus, the rate at which streams process terrestrial DOM remains unconstrained (Battin et al. 2009, Mineau et al. 2016, Catalán et al. 2018), and empirical measures of DOM processing are needed to better model DOM processing at multiple temporal and spatial scales.

DOM decay is often measured with bioassays, which include any closed-system incubations (e.g., dark bottles, Erlenmeyer flasks) that are used to measure changes in DOM

E-mail addresses: ${ }^{3}$ Present address: Oak Ridge Institute for Science and Education fellow, Environmental Protection Agency, Office of Water $4101 \mathrm{M}, 1200$ Pennsylvania Avenue Northwest, Washington DC, 20460 USA, julia.kelso@gmail.com; ${ }^{4}$ rosie@caryinstitute.org; ${ }^{5}$ michelle.baker@usu.edu 
concentration or composition over time. Such assays are problematic because most incubations do not include a proxy for the benthic or littoral zone of aquatic ecosystems (Catalán et al. 2016, Mineau et al. 2016, Bengtsson et al. 2018). Sediments at the interface of the water column and deeper sediments, in both streams and lakes, represent hot spots of microbial density and diversity (Guenet et al. 2010), and benthic habitats contribute to at least half of stream DOM demand (Cory and Kaplan 2012, Risse-Buhl et al. 2012). Further, bioassay results are difficult to compare across studies because incubation times vary from days to years, and bioassays may or may not include sediment (van Nugteren et al. 2009), inorganic substrates (e.g., glass beads; Catalán et al. 2015, Ward et al. 2016), or aeration to maintain realistic dissolved oxygen concentrations (Lock and Hynes 1976, Qualls and Haines 1992). More studies that include flow-through conditions and benthic compartments, such as mesocosms and experimental streams, are needed to put bioassay studies in context and to constrain realistic DOM decay rates (Mineau et al. 2016, Halvorson et al. 2019).

Another major shortcoming of bioassays is that they do not account for the effects of sunlight exposure on DOM composition. Photodegradation can reduce the molecular weight of DOM, but the degree of degradation depends on the chemical composition of the DOM prior to sunlight exposure (Moran et al. 2000, Chen and Jaffé 2014). For example, the greater the proportion of aromatic content, the greater the effect of sunlight on bioavailability (Moran et al. 2000, Tranvik and Bertilsson 2001). However, the highly-variable chemical composition of DOM has yielded unpredictable effects of sunlight exposure on DOM lability. Sunlight can increase (Moran and Zepp 1997), decrease (Tranvik and Bertilsson 2001), or have no effect (Wiegner and Seitzinger 2001) on DOM bioavailability.

DOM chemical composition mediates microbial consumption of DOM and is, therefore, an important control of DOM decay (Koehler et al. 2012, Mostovaya et al. 2016). Most of the freshwater DOM pool is derived from terrestrial sources, and the remainder is assumed to be derived from autochthonous sources, i.e., OM produced instream from biofilms, algae, and macrophytes (Findlay and Sinsabaugh 2003). Terrestrial sources, such as soil and plant leachates, are typically rich in humic constituents and are considered less biologically available to stream microbes than autochthonous sources (Findlay and Sinsabaugh 2003). Autochthonous DOM consists of low molecular weight, protein-rich cellular exudates produced during photosynthesis and is considered one of the primary labile sources of DOM preferred by microbes (Guillemette et al. 2013). Hereafter, we operationally define the relative lability of DOM leachates used in this study as semi-labile for terrestrially-derived DOM and labile for autochthonously-derived DOM. We avoid the term recalcitrant because it is controversial (Bengtsson et al. 2018) and because substrate recalcitrance can vary depending on the microbial assemblage and environmental conditions (Bengtsson et al. 2014, 2018).

It is important to accurately estimate decay of labile and semi-labile DOM pools to better understand how interactions between labile and semi-labile DOM influence the DOM decay rate. When mixed, these 2 pools are hypothesized to have non-additive effects on microbial degradation rates (Guenet et al. 2010, Bengtsson et al. 2018). First reported in soil ecosystems, such effects are traditionally referred to as priming effects. We use the term non-additive effects as suggested by Bengtsson et al. (2018) because positive non-additive effects are overrepresented in the aquatic priming literature, and we want to reduce potential researcher bias when interpreting our results. Non-additive effects can be both positive or negative and describe an increase or decrease in the decay rate of the semi-labile organic matter pool when combined with labile DOM. Positive non-additive effects are expected to occur in aquatic systems because exudation of low molecular weight, nutrient-rich compounds produced during photosynthesis spur microbial consumption of semi-labile substrates (Danger et al. 2013, Guillemette et al. 2013). Bioassay studies that added simple compounds (e.g., disaccharides, acetate) and algal-derived DOM to semi-labile DOM have reported positive non-additive effects (Hotchkiss et al. 2014, Bianchi et al. 2015), while others have found no effect or negative nonadditive effects (Bengtsson et al. 2014, Catalán et al. 2015). It would be significant to quantify positive non-additive effects in streams because these effects are proposed as a mechanism to explain the rapid transformation of semi-labile DOM over short distances in stream networks (Hotchkiss et al. 2014, Mineau et al. 2016), and it would inform models of ecosystem organic carbon flux.

Given that positive non-additive effects could be an important mechanism to explain rapid OM processing in streams, as well as the difficulties in quantifying DOM decay in aquatic ecosystems, this study addressed 2 different but inextricably-linked questions. First, do laboratory measures of DOC decay in bioassays and experimental streams reflect reality? For example, are decay rates measured in bioassays and experimental streams comparable to each other or to real streams? Second, can non-additive effects of mixing labile and semi-labile DOM be quantified in laboratory aquatic systems? To address the $1^{\text {st }}$ question, we conducted 5 singlesource leachate incubations to measure decay of 2 types of semi-labile DOM (soil and plant leachates) and 3 types of labile DOM (algal-derived leachate, light-degraded plant leachate, and light-degraded soil leachate; Fig. 1). We expected DOC decay rates to be faster in experimental streams compared to bioassays because of benthic microbial activity in experimental streams. We also expected that terrestrial leachates high in aromatic content would become more labile when exposed to sunlight as reflected by lower aromatic content and faster decay rates. We then compared DOC decay rates from this study to other published $1^{\text {st }}$-order decay rates 


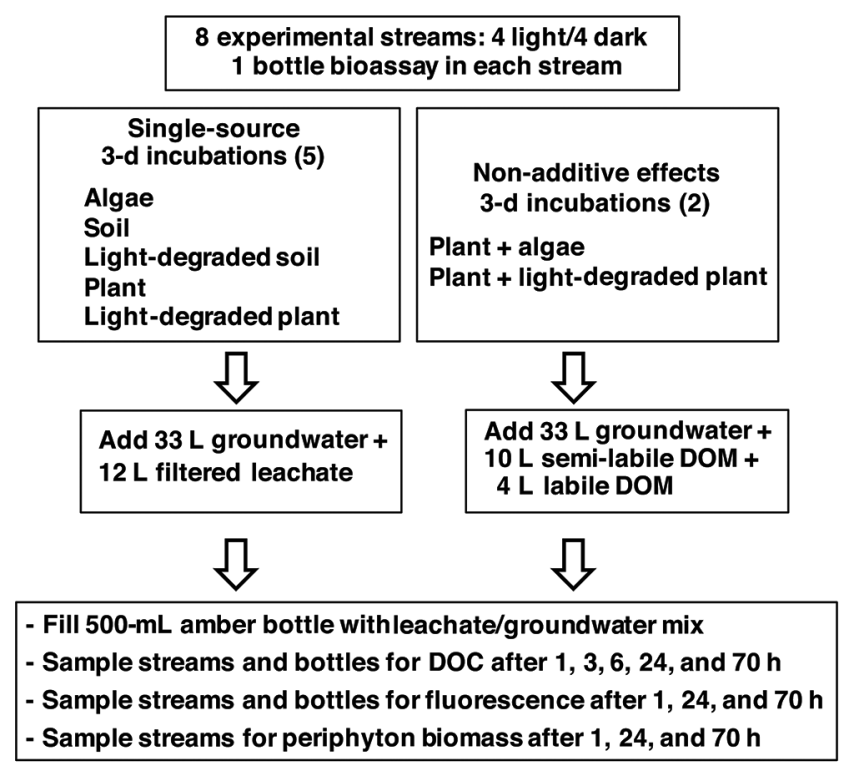

Figure 1. Experimental design used to calculate dissolved organic carbon (DOC) decay rates of algal, soil, light-degraded soil, plant, and light-degraded plant dissolved organic matter (DOM; 5 single-source incubations) and calculate positive or negative non-additive effects on the decay rates of plant DOM when mixed with algal leachate and light-degraded plant leachate ( 2 non-additive effects incubations). Four streams were covered to exclude sunlight for the dark treatment, and 4 streams were left uncovered for the light treatment.

in bioassays and real streams to see if experimental stream decay rates could constrain estimates of DOM decay in lotic systems. To address the $2^{\text {nd }}$ question, we conducted 2 nonadditive effects incubations by mixing 2 forms of labile DOM with semi-labile DOM (Fig. 1). We anticipated that mixing labile DOM with semi-labile DOM would result in faster DOC decay rates of the semi-labile pool (i.e., positive non-additive effects).

\section{METHODS}

To address our $1^{\text {st }}$ research question, we conducted a series of 3-d incubations in both experimental streams and bottle bioassays (hereafter bioassays) with DOM leachates from either algal, terrestrial, or light-degraded terrestrial sources. We calculated $1^{\text {st }}$-order decay coefficients for the decline in DOC concentrations over time as a proxy for decay of the entire DOM pool. For all incubations we estimated decay rates after 6,24 , and $70 \mathrm{~h}$ because DOC concentrations are thought to decline very rapidly within the first $24 \mathrm{~h}$ of incubation (Pollard 2013, Bowen et al. 2019) but are rarely measured in the $1^{\text {st }}$ few hours of incubations. Then, we compared decay rates and \% biodegradable DOC (BDOC) between experimental streams and bioassays in this study and among decay rates, half-lives, and uptake velocities in previous studies that estimated DOM decay in bioassays and real streams. DOM is a complex and variable mixture of chemical compounds, so comparison of decay rates to previous studies resulted in evaluation of a wide range of proxies for labile DOM (e.g., simple sugars, algal leachate) and semilabile DOM (e.g., leaf and soil leachate, humate) as well as whole samples of naturally-occurring riverine DOM (bulk DOM).

To address our $2^{\text {nd }}$ question, we first confirmed several assumptions required to quantify non-additive effects in experimental streams and bioassays. First, we used Bayesian estimation supersedes the $t$-test (BEST; Kruschke 2013) to compare decay rates between labile and semi-labile sources to confirm that algal and light-degraded semi-labile leachates did in fact decay faster that semi-labile leachates. Then, we used fluorescence metrics of DOM to further characterize DOM leachates as labile or semi-labile based on DOM chemical composition and to characterize changes in DOM composition caused by exposure to sunlight. We also measured benthic biomass to ensure that any differences in DOM decay were due to differences in the DOM source rather than variability associated with benthic biomass among experimental streams or among incubations over time. We then estimated concurrent decay rates of labile and semi-labile leachates in non-additive effects incubations by fitting 2compartment, bi-exponential and bi-phasic, DOC decay models to the decline in DOC concentrations over time.

\section{Experimental streams}

We conducted incubations in 8 experimental streams at the Cary Institute of Ecosystem Studies Artificial Stream Facility in Millbrook, New York, USA. Streams were housed in a greenhouse covered with 8-mm, high-impact, double-skinned acrylic (Acrylic Building Products, Mississauga, Ontario, Canada) estimated to transmit $84 \%$ of photosynthetically-active radiation. In all incubations, we filled the fiberglass artificial streams $(4.0 \times 0.3 \times 0.15 \mathrm{~m})$ with $33 \mathrm{~L}$ of groundwater that had low levels of DOC ( $<1.0 \mathrm{mg} / \mathrm{L}$; Fig. 1$)$. We used stainless steel paddle wheels propelled by Dayton DC gear motors (Dayton, Niles, Illinois) to circulate water in the streams at 45 rotations $/ \mathrm{min}$, yielding a mean water velocity of $0.6 \mathrm{~m} / \mathrm{s}$. We added 40 cobbles, already colonized with periphyton, to each stream to compare DOC consumption in experimental streams containing benthic biofilms vs bioassays without biofilms. We collected the cobbles from an open-canopy section of the East Branch of Wappinger Creek within the Cary Institute of Ecosystem Studies conservation research area. We put cobbles in streams $48 \mathrm{~h}$ prior to the first 3-d incubation, and we used the same cobbles for all seven 3-d incubations.

\section{Leachates}

To make algal leachate, we put biofilm-covered cobbles (from East Branch Wappinger Creek) in 19-L buckets, covered them with groundwater, and scrubbed them to create a biofilm slurry, which we incubated for 1 to $2 \mathrm{~h}$ in the 
bucket before filtering. To make soil leachate, we collected soil by digging 10 to $30 \mathrm{~cm}$ into the riparian zone of Wappinger Creek, stirred $4 \mathrm{~L}$ of this soil with $10 \mathrm{~L}$ of groundwater, and allowed particulates to settle in 19-L buckets for 2 to $4 \mathrm{~h}$ prior to filtration. We made plant leachate from concentrated roasted barley leachate. We chose to use barley because it is readily available, and ongoing work by our group has shown that aromatic fluorophores in barley leachate are degraded by exposure to sunlight without changing the DOC concentration. We obtained pre-roasted malt barley from a brewery supply store and made a concentrate by adding $60 \mathrm{~g}$ of ground, roasted barley to $1 \mathrm{~L}$ of groundwater. To make plant leachate, we added $5 \mathrm{~mL}$ of this concentrate to $1 \mathrm{~L}$ of groundwater. To make light-degraded soil and plant leachates, we incubated soil and plant leachates (made as described above) in $0.5 \times 1.0 \times 0.2$-m trays in full sun for 3 to $4 \mathrm{~h}$. Soil and plant leachates were exposed to sunlight for what we considered the minimum amount of time DOM would be exposed to natural sunlight in a temperate, forested stream with a short travel time $(<1 \mathrm{~d})$. We used 0.2- $\mu \mathrm{m}$-pore, in-line cartridge filters (Waterra Pumps Limited, Mississauga, Ontario, Canada) to filter-sterilize all leachates.

\section{Experimental design}

We conducted 5 single-source incubations followed by 2 non-additive effects incubations over the course of $22 \mathrm{~d}$ in July 2016. Non-additive effects incubations included 2 sources of DOM (a labile plus semi-labile source). One bioassay was incubated in each stream to compare DOC decay in bioassays and experimental streams during each 3-d incubation (Fig. 1). We chose an incubation period of $3 \mathrm{~d}$ because labile DOM is known to decay within days to hours (Pollard 2013, Bowen et al. 2019). To eliminate production of labile DOM from photosynthesis during the day and to ensure DOC concentrations declined over time, we covered 4 experimental streams with cardboard (dark treatment). The remaining 4 streams were not covered (light treatment). Streams in the light treatment experienced natural daily fluctuations in sunlight to promote more realistic decay rates than in the dark treatment. Temperature, which was monitored every 15 min with miniDOT ${ }^{\circledR}$ loggers (Precision Measurement Engineering, Vista, California), ranged from 15 to $35^{\circ} \mathrm{C}$ in dark streams and 13 to $36^{\circ} \mathrm{C}$ in light streams.

At the beginning of single-source incubations, we added $12 \mathrm{~L}$ of filter-sterilized leachate resulting in $26 \%$ of total stream volume as leachate (Fig. 1). We added leachates at sunset to maximize the duration of darkness at the beginning of each incubation to avoid excessive DOC production from photosynthesis in the light treatment. After adding leachate and allowing it to mix in the stream, we set up bioassays by filling $500-\mathrm{mL}$ amber bottles with experimental stream water and placing 1 bottle in each stream for the remainder of the incubation period. We conducted single-source incubations in the following or- der: algae, soil, light-degraded soil (SoilLight), plant, and light-degraded plant (PlantLight). The algal leachate incubation was conducted first because it took much less time to prepare and filter algal leachate compared to soil leachate. Light-degraded incubations were conducted after nonlight degraded incubations because leachate needed several hours of sunlight exposure prior to incubations. Between each 3-d incubation, experimental streams were drained and filled with groundwater to begin the next incubation.

Following single-source incubations, we conducted two 3 -d incubations in both experimental streams and bioassays where we mixed 2 forms of labile DOM (algal and PlantLight DOM) with semi-labile plant DOM. We used plant leachate as the semi-labile source of DOM in non-additive effects incubations because roasted barley produced a more homogenous and replicable DOC source than soil. In addition, single-source soil leachate incubations only reached maximum concentrations of $\sim 4 \mathrm{mg} / \mathrm{L} \mathrm{DOC}$, so it was difficult to detect substantial declines in DOC concentrations and estimate decay rates (Fig. S1). For each non-additive effect incubation, we mixed $10 \mathrm{~L}$ of plant leachate with $4 \mathrm{~L}$ of labile DOM, either as algae (PrimeAlgae incubation) or light-degraded plant leachate (PrimeLight incubation).

In all incubations we sampled DOC prior to adding leachate and 1, 3, 6, 24, and $70 \mathrm{~h}$ after leachate additions (Fig. 1). We used a $60-\mathrm{mL}$ plastic syringe to sample bioassays and experimental streams at the same times. We filtered all samples with $0.7-\mu \mathrm{m}$ glass-fiber filters (Whatman ${ }^{\circledR} \mathrm{GF} / \mathrm{F}$; Maidstone, United Kingdom) into 40-mL amber vials and acidified the filtrate with an aliquot of concentrated $\mathrm{HCl}$ to a $\mathrm{pH}$ of 2.5 for storage until carbon analysis. Acidified DOC samples were run on a Shimadzu ${ }^{\text {TM }}$ TOC-L analyzer (Shimadzu Corporation, Kyoto, Japan) via catalytic oxidation combustion at $720^{\circ} \mathrm{C}$ (method detection limit: $0.62 \mathrm{mg} / \mathrm{L} \mathrm{DOC}$ ).

\section{BDOC in bioassays and experimental streams}

We calculated BDOC, which represents total DOC loss over the incubation period, as the \% loss in DOC concentration from 3 to $70 \mathrm{~h}$ (Fellman et al. 2008). We calculated BDOC from 3 to $70 \mathrm{~h}$ because DOC concentrations increased for the first $3 \mathrm{~h}$ of all bioassays except the PlantLight and PrimeAlgae incubations (Fig. S1). These increased concentrations were likely due to cell lysis and DOM production similar to previous DOM bioassay studies (e.g., Hosen et al. 2014, Bianchi et al. 2015). We tested for differences among leachate BDOC in bioassays and experimental streams with the Kruskal-Wallis rank sum test followed by post-hoc comparisons with pairwise Wilcoxon rank sum tests because these tests are most appropriate for nonparametric data. Kruskal-Wallis and Wilcoxon rank tests were done in $\mathrm{R}$ (version 3.6.1; R Project for Statistical Computing, Vienna, Austria) with the stats package. We used the rstatix package (version 0.5.0; Kassambara 2020) to calculate eta squared $\left(\eta^{2}\right)$, a measure of effect size. 


\section{DOC decay in bioassays and experimental streams}

We assumed single-source decay would fit a $1^{\text {st }}$-order decay model and mixed incubations of labile and semi-labile DOM would fit 2-compartment decay models. We estimated decay coefficients with Bayesian parameter estimation for 2 reasons. First, unlike null hypothesis testing, Bayesian parameter estimation produces posterior probability distributions, which include a highest density interval (HDI) that represents the most credible values of the parameter (Kruschke 2013). The difference in HDIs of 2 parameters represents an effect size and can be interpreted as the magnitude of difference in the parameters (Kruschke 2013). Comparisons of the effect size between labile and semi-labile decay rates allowed us to interpret decay rates calculated for labile DOM as a little faster, or a lot faster, than semi-labile decay rates. In contrast, null hypothesis testing produces a $p$-value, which only allows the conclusion that decay rates were or were not significantly different. Second, by using Bayesian parameter estimation for 2-compartment decay models, we could use decay rates calculated from single-source models to inform parameter estimation in 2-compartment models, thereby improving model fit with prior information.

Single-source DOC decay incubations We calculated decay rates for all incubations after 6, 24, and 70 h. Singlesource decay rate constants were estimated with Bayesian parameter estimation with the following equation:

$$
C_{\mathrm{t}}=C_{0} e^{-k_{\text {tot }} t}
$$

where $k$ is the decay rate with unit $1 / \mathrm{d}$, and $C_{0}$ and $C_{\mathrm{t}}$ represent DOC concentrations at the start and end of the period over which total decay $\left(-k_{\text {tot }}\right)$ was calculated over time $(t)$.

\section{Comparison of DOC decay among bioassays, experimental streams, and real streams}

To put DOC decay rate constants calculated for bioassays and experimental streams in context with DOC decay measured in real streams, we transformed DOC decay rate constants to half-lives and uptake velocities. We converted decay rates to half-lives because we considered half-lives a more intuitive metric of DOC loss over time than decay rates (e.g., units of $1 / \mathrm{d}$ for decay rates vs days for half-lives), and half-lives simplify comparisons of OM loss over time among different aquatic and terrestrial ecosystems (e.g., Catalán et al. 2016). Uptake velocities transform decay rate constants to a carbon-demand metric specific to streams that describe the rate of OM transformation with distance downstream and are often calculated to compare streams that vary in size (Webster and Valett 2007). We calculated half-lives by dividing the natural $\log$ of 2 by the decay rate constant. We calculated uptake velocities $\left(V_{f}\right)$ for experimental streams and bioassays by dividing experimental stream depth, $z(0.07 \mathrm{~m})$, by the decay rate of DOC (Webster and Valett 2007):

$$
V_{f}=z k^{-1}
$$

We used BEST tests (Kruschke 2013) in R to compare BDOC, decay rate constants, half-lives, and uptake velocities between bioassays and experimental streams in this study. We considered DOC demand metrics to be different if the difference in 95\% HDIs did not include 0 (Kruschke 2013).

To compare our bioassay and experimental stream results to real streams, we extracted DOM decay rates from 2 previous papers that compared DOM decay rates for real streams and bioassays (Mineau et al. 2016, Catalán et al. 2018) as well as 5 additional papers that calculated DOM decay or DOM uptake velocities of riverine DOM (Guillemette and del Giorgio 2011, Parr et al. 2015, Epstein et al. 2016, Logue et al. 2016, Ward et al. 2016; Table S2). We classified decay rates as labile or semi-labile based on descriptions in the study, and we classified bulk DOM as semi-labile. For experimental stream estimates of DOM decay, we averaged $1^{\text {st }}$ order decay estimates for all 8 streams, or 8 bottle bioassays, calculated over 6,24 , and $70 \mathrm{~h}$ (Table S2). We excluded averaged decay rates estimated from single-source incubations from the comparison if the coefficient of variation (CV) among 8 experimental streams or 8 bioassays within an incubation was $>100 \%$. This approach allowed us to use only the most precise estimates of $1^{\text {st }}$-order decay from this study for comparison to previously-reported DOM demand metrics. We tested for differences among DOC demand metrics among the 3 methods (i.e., bioassays, experimental streams, and real streams) with a Kruskal-Wallis rank sum test followed by post-hoc comparisons made with pairwise Wilcoxon rank sum tests because these tests are most appropriate for nonparametric data. We ran Kruskal-Wallis and Wilcoxon rank tests in $\mathrm{R}$ with the stats package and calculated $\eta^{2}$ with the rstatix package (Kassambara 2020).

\section{Confirmation of assumptions needed to quantify non-additive effects}

Labile vs semi-labile decay rates We used the difference in decay rates for labile and semi-labile DOM estimated from single-source models to confirm that labile sources of DOM (algae, SoilLight, PlantLight) decayed faster than semi-labile sources (soil, plant). We calculated the difference by subtracting the 95\% HDI of semi-labile DOM from the $95 \%$ HDI of labile DOM. If the median difference was greater than 0 , we considered the decay rates substantially different (Hotchkiss et al. 2014).

\section{DOM composition and lability characterized by fluorescence}

We sampled filtered water from streams and bioassays for spectrofluorometric analysis after 1,24 , and $70 \mathrm{~h}$ with the same methods used to sample DOC, except fluorescence 
samples were not acidified. We collected excitation emission matrices (EEMs) on an Aqualog ${ }^{\circledR}$ scanning spectrofluorometer (HORIBA Scientific, Kyoto, Japan). We used fluorescence to assess changes in DOM character through each 3-d incubation and to calculate DOM fluorescence indices that characterized DOM as either microbial or humiclike and, therefore, more labile or semi-labile, respectively. EEMs were collected in a 1-cm quartz cuvette over excitation wavelengths from 248 to $830 \mathrm{~nm}$ at $6-\mathrm{nm}$ increments and over emissions 249.4 to $827.7 \mathrm{~nm}$ at $4.7-\mathrm{nm}$ (8 pixel) increments. We collected all samples in ratio mode $(S / R)$ and ran them at an integration time resulting in a maximum emission intensity of 5000 to 50,000 counts/s (per manufacturer instructions; R. Cory, University of Michigan, personal communication). We used deionized water to dilute samples that exceeded 0.3 absorbance at excitation $254 \mathrm{~nm}$. We corrected all samples for inner filter effects and Rayleigh scatter and blank subtracted them in MATLAB (version 6.9; MathWorks, Natick, Massachusetts) as described in Murphy et al. (2013).

From EEMs, we calculated the fluorescence index (FI), $\beta: \alpha$ index or freshness index (BIX), humification index (HIX), and peak $\mathrm{T}$ to peak $\mathrm{C}$ ratio (TC). High vs low FI values indicate microbial vs terrestrially-derived DOM (Cory and McKnight 2005). Greater values of the BIX indicate more recently-derived DOM (Parlanti et al. 2000), and greater HIX values indicate more humic-like DOM (Zsolnay et al. 1999). The TC index represents the ratio of the protein-like peak (T) to humic-like peak (C) intensities (Baker 2001). We calculated specific ultraviolet absorbance (SUVA), an indicator of DOM aromatic content, by normalizing the absorbance at $254 \mathrm{~nm}$ by the DOC concentration of each sample (Weishaar et al. 2003).

To assess changes in DOM throughout each incubation (e.g., a decline in humic-like components due to light exposure), we used parallel factor analysis (PARAFAC) to identify fluorescence components of DOM. PARAFAC decomposes a collection of EEMs into groups of organic compounds with similar fluorescent characteristics (Stedmon and Markager 2005). We used the drEEM toolbox in MATLAB following Murphy et al. (2013) to create a PARAFAC model with 213 EEMs. We then validated the model with split-half analysis and compared resolved components to previously-found fluorophores in the open source library OpenFluor with Tucker's congruence coefficients $>0.95$ (Murphy et al. 2014). We used Pearson's correlations in $\mathrm{R}$ with the psych package (version 1.7.8; Revelle 2017) to correlate the percentage of each PARAFAC component with fluorescence indices.

We ran 10 linear models to identify incubations that best described variation in fluorescence indices and PARAFAC components. Linear models tested the fixed effects of: 1) leachate incubation, 2) leachate incubation plus bottles vs streams, 3) leachate incubation plus light streams vs dark streams, and 4) the interaction of leachate incubation and light vs dark streams. We used samples collected after $70 \mathrm{~h}$ to assess differences in fluorescence indices and PARAFAC components because that is when differences were greatest. We calculated Bayes factors to identify the linear model that best described variation in dependent variables. The Bayes factor $\left(B_{01}\right)$ can be generalized as the probability ratio between 2 models $\left(M_{0}, M_{1}\right)$ :

$$
B_{01}=\frac{\operatorname{Pr}\left(\text { Data } \mid M_{0}\right)}{\operatorname{Pr}\left(\text { Data } \mid M_{1}\right)}
$$

We calculated Bayes factors with the R package BayesFactor (version 0.9.12-2; Rouder et al. 2012) for models normalized by the effect of incubation alone. Once the linear model that best described variation in dependent variables was identified through comparison of relative Bayes factors, we tested differences in fluorescence metrics among incubations with Tukey honestly significant difference (HSD) comparison because residuals were normally distributed. Tukey HSD multiple means comparisons were conducted with the stats package.

Benthic biomass We characterized periphyton biomass by measuring the concentration of chlorophyll $a(\mathrm{Chl} a)$ and ash-free dry mass (AFDM) of periphyton slurry and normalizing it to cobble area. To collect periphyton biomass, we took 1 cobble from each experimental stream after 1, 24, and $70 \mathrm{~h}$, scrubbed it with a toothbrush, and washed it with an aliquot of groundwater. We filtered a 3-mL subsample of periphyton slurry from each cobble through GF/F filters and analyzed the filtrate for Chl $a$ and AFDM following Steinman et al. (2007). We normalized Chl $a$ and AFDM by the area $\left(\mathrm{cm}^{2}\right)$ of each cobble sampled. We tested differences in AFDM and Chl $a$ among leachate incubations with a 1-way analysis of variance (ANOVA), $\eta^{2}$ effect size, and Tukey HSD post-hoc tests because data were normally distributed with equal variances. We did 1-way ANOVAs and posthoc tests in $\mathrm{R}$ with the stats package ( $\mathrm{R}$ Core Team 2019) and calculated $\eta^{2}$ with the sjstats package (version 0.17.9, Lüdecke 2020).

\section{Quantification of non-additive effects}

We did not know if the DOC decay of mixed labile and semi-labile pools would better fit a model of simultaneous 2-compartment decay, as in a biexponential model (e.g., Hotchkiss et al. 2014), or sequential 2-compartment decay, as in a biphasic model (e.g., Eichmiller et al. 2016, Brouwer et al. 2017), so we estimated labile and semi-labile decay coefficients with both biexponential and biphasic decay models. The biexponential decay model assumed the labile $\left(k_{\text {fast }}\right)$ and semi-labile $\left(k_{\text {slow }}\right)$ pools of DOC decayed simultaneously starting at time $0\left(t_{0}\right)$ :

$$
\left.C_{\mathrm{t}}=p_{1} C_{1(t 0)} e^{-k_{\text {fast }} t}+p_{2} C_{2(t 0)} e^{-k_{\text {slow }} t} \quad \text { (Eq. } 4\right),
$$


where $C_{\mathrm{t}}$ is the total concentration of both labile $\left(C_{1}\right)$ and semi-labile $\left(C_{2}\right)$ pools at the start of the incubation, and $p_{1}$ and $p_{2}$ are the proportional volumes of each leachate (Hotchkiss et al. 2014; Appendix S3).

The biphasic decay model assumed there was a fast period of decay followed by a slow period of decay (Eichmiller et al. 2016, Brouwer et al. 2017). For the biphasic model, $k_{\text {fast }}$ was estimated with $1^{\text {st }}$-order exponential decay up to a breakpoint at time $t^{*}$ (Eq. 5 ), and $k_{\text {slow }}$ was estimated for the period of decay after the breakpoint with the value estimated for $k_{\text {fast }}$ prior to the breakpoint (Eq. 6; Appendix S3).

$$
\begin{gathered}
C_{t^{*}}=C_{0} e^{-k_{\text {fast }} t} t<t^{*} \\
C_{\mathrm{t}}=C_{0} e^{-k_{\text {fast }} t^{*}} e^{-k_{\text {slow }}\left(t-t^{*}\right)} t>t^{*}
\end{gathered}
$$

Using traditional methods of breakpoint analysis (e.g., segmented or changepoint analysis), there were not enough time points to identify the breakpoint between fast and slow periods of decay. Therefore, we estimated breakpoints visually from raw DOC concentrations plotted over $70 \mathrm{~h}$.

We estimated the decay rates of each compartment with Bayes rule where the posterior probability distribution of $k_{\text {fast }}$ and $k_{\text {slow, }}$ given the DOC data, is proportional to the product of the likelihood of the decay model and the prior probability distributions of the decay parameters (Hotchkiss et al. 2014). The posterior probability distributions of $k_{\text {fast }}$ and $k_{\text {slow }}$ were simulated with the rjags package (version 4.2.0; Plummer
2013) using Markov Chain Monte Carlo sampling from a prior distribution informed by the results of the single-source incubations. We ran each model for 150,000 iterations using 3 different starting values for each chain, and the first 10,000 samples were not included in parameter estimation. We assessed model fit through linear regression of measured versus predicted values of DOC concentrations at the last modeled time point (Hotchkiss et al. 2014).

To test if positive non-additive effects were significant (i.e., positive priming effect), we subtracted the 95\% HDI for single-source plant DOC decay $k_{\text {tot }}$ from the 95\% HDI of the slow decay compartment $\left(k_{\text {slow }}\right)$. If the median difference in the $95 \%$ HDI of the 2 distributions $\left(k_{\text {slow }}-k_{\text {tot }}\right)$ was $>0$, we considered it to be a positive non-additive effect (Hotchkiss et al. 2014).

\section{RESULTS}

\section{BDOC in bioassays and experimental streams}

Overall, \% BDOC was $30 \%$ greater in experimental streams (mean $52.6 \% \pm 20.3$ standard deviation [SD]) than bioassays (mean: 22.8\% \pm 12.3 SD; BEST 95\% HDI = 22.636.7\%; Fig. 2). Soil leachate BDOC in experimental streams (mean: $-8.2 \pm 18.3 \% \mathrm{SD}$ ) was lower than all other experimental stream BDOC values, which had means that ranged from 50.5 to $58.2 \%$ (Kruskal-Wallis ANOVA, $\mathrm{df}=4, \chi^{2}=$ 45.66, $p<0.01, \eta^{2}=0.44$ ). Algal leachate BDOC (mean: $33.9 \pm 4.7 \%)$ was greater than plant leachate BDOC $(9.7 \pm$ $15.1 \%)$, but there were no differences in BDOC among

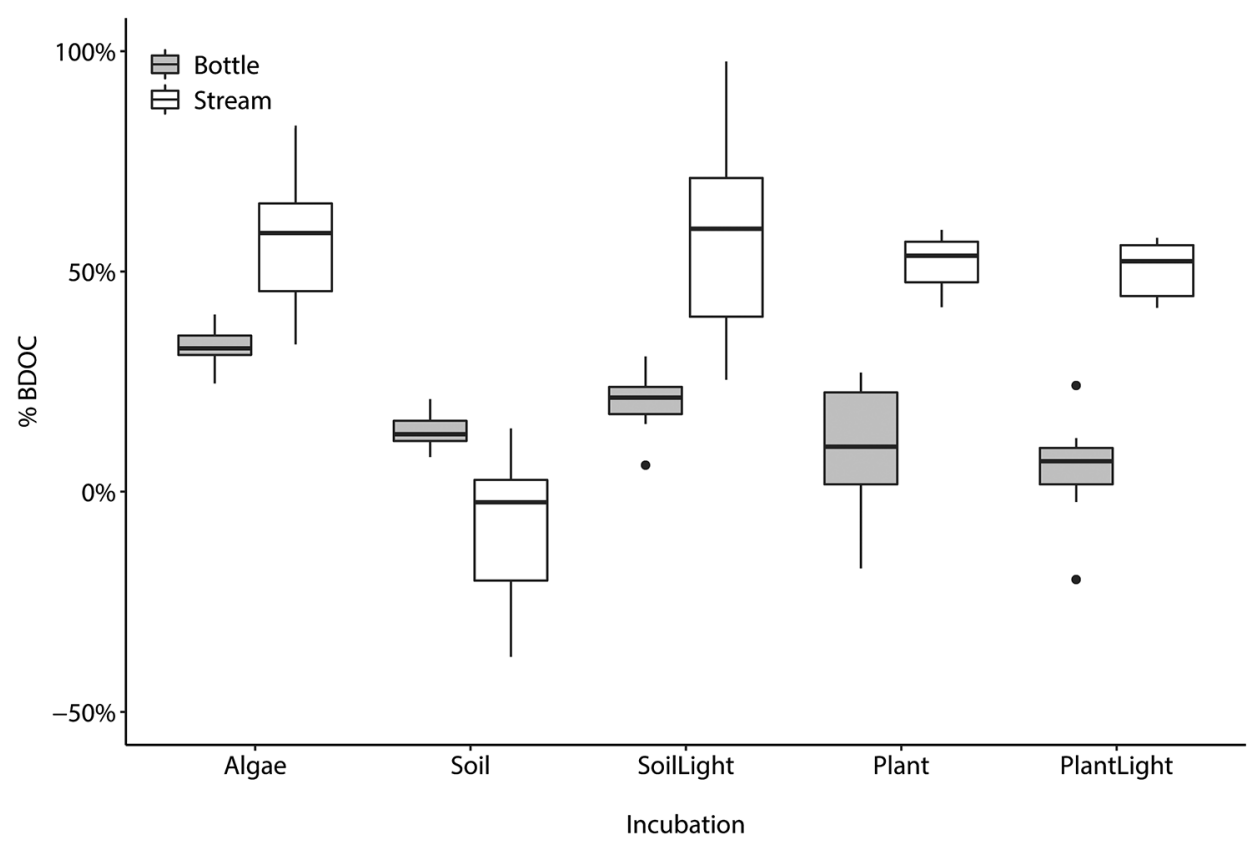

Figure 2. Comparison of biodegradable dissolved organic carbon (BDOC) between bottle bioassays (open boxes, $n=8$ ) and experimental streams (gray boxes, $n=8$ ) with algal, soil, light-degraded soil (SoilLight), plant, and light-degraded plant (PlantLight) leachates. Boxes represent the median and interquartile range, whiskers represent the 2.5 to 97.5 percentile range, and dots are outliers. 
other leachate BDOC values in bioassays (Kruskal-Wallis ANOVA, $\left.\mathrm{df}=4, \chi^{2}=37.59, p<0.01, \eta^{2}=0.46\right)$.

\section{DOC decay in bioassays and experimental streams}

We excluded the average decay rates from some singlesource incubations because the CV was $>100 \%$ for 2 experimental stream decay rates calculated after $24 \mathrm{~h}$ (SoilLight CV: $128 \%$, Soil CV: $287 \%$ ) and 4 bottle decay rates (Plant24. h CV: 183\%, Soil-70 h CV: 377\%, SoilLight-6 h CV: 612\%, PlantLight-70 h CV: 331\%). DOC decay rates from single-source incubations of experimental streams in this study ( $n=13$, median: $0.23 / \mathrm{d} \pm 0.89 \mathrm{SD})$ were not different from decay rates of bottle bioassays ( $n=11$, median: $0.19 / \mathrm{d} \pm$ 0.53 SD; BEST 95\% HDI $=-0.43-0.90 \%)$. Likewise, DOC half-lives (median: 1.49/d $\pm 2.78 \mathrm{SD}$ ), and uptake velocities (median: $0.01 \mathrm{~mm} / \mathrm{min} \pm 0.04 \mathrm{SD}$ ) in experimental streams were not different from bioassay half-lives (median: $2.74 \mathrm{~d} \pm$ 4.92 SD; BEST 95\% HDI $=-6.76-2.79 \%$ ) or uptake velocities (median: $0.01 \mathrm{~mm} / \mathrm{min} \pm 0.03 \mathrm{SD}$; BEST 95\% HDI $=-0.22-$ $0.04 \%)$.

\section{Comparison of DOC decay among bioassays, experimental streams, and real streams}

We compared DOC decay rates, half-lives, and uptake velocities among 3 methods (bioassays, experimental streams, and real streams) used to measure DOC demand in the literature. However, the number of studies that used each method varied greatly (Table S2). Of the 3 methods we compared, the most common DOC demand metric reported was uptake velocity of labile DOC additions to real streams $(n=$ 79; Table 1), and most labile DOC additions were in the form of simple compounds including glucose, arabinose, and sucrose (76 of 79 measurements; Table S2). There were only 2 studies that reported uptake velocities of labile leachates created with naturally-occurring sources of DOM (manure: $0.31 \mathrm{~mm} / \mathrm{min}$, fish carcass leachate: $3.78 \mathrm{~mm} / \mathrm{min}$; Mineau et al. 2016). Decay rates of semi-labile DOC in bioassays were the next most commonly reported metric $(n=32)$, followed by semi-labile uptake velocities from bioassays $(n=19)$. Experimental streams were the least reported method because ours was the only experimental stream study included in the comparison.

In general, metrics of DOC loss were greater in real streams compared to experimental streams and bioassays. For example, mean decay rates and uptake velocities of DOC were at least an order of magnitude faster in real streams compared to bioassays and experimental streams (Table 1). Lower mean decay rates in experimental streams and bioassays may have been due to the inclusion of several negative decay rates (bioassays: $n=2$, experimental streams: $n=3$ ), which indicated that measures of DOC loss also included DOC production. Transformation of decay rates to half-lives resulted in experimental stream DOC loss rates that were more similar to real streams than bioassays (Table 1). For example, in streams, mean labile DOC decay rates $(60.48 / \mathrm{d} \pm 39.7 \mathrm{SD})$ and uptake velocities $(3.25 \mathrm{~mm} / \mathrm{min} \pm$ 4.1 SD) were faster than labile DOC decay rates $(0.98 / \mathrm{d} \pm$ $2.5 \mathrm{SD})$ and uptake velocities $(0.04 \mathrm{~mm} / \mathrm{min} \pm 0.03 \mathrm{SD})$

Table 1. Kruskal-Wallis rank sum comparisons of mean and standard deviation for dissolved organic matter (DOM) demand in bioassays, experimental streams, or real streams. Comparisons were conducted for 2 categories of DOM bioavailability, either labile or semi-labile DOM. Models were evaluated for an $\alpha$ value of 0.05 , and eta-squared $\left(\eta^{2}\right)$ effect sizes were considered large if $>0.26$ (Cohen 1988). Letters a and b represent differences detected by pairwise Wilcoxon rank sum tests among the 3 methods. See Table S2 for references of previous studies. $n=$ number of streams.

\begin{tabular}{|c|c|c|c|c|c|c|c|c|}
\hline Category and effect & $n$ & Decay $(1 / d)$ & & Half-life (d) & & $n$ & Uptake velocity $(\mathrm{mm} / \mathrm{min})$ & \\
\hline \multicolumn{9}{|l|}{ Labile } \\
\hline Bioassays & 14 & $0.98 \pm 2.50$ & a & $4.82 \pm 5.91$ & a & 12 & $0.04 \pm 0.03$ & $\mathrm{a}$ \\
\hline Experimental streams & 8 & $0.88 \pm 1.10$ & a & $1.26 \pm 1.90$ & $\mathrm{ab}$ & 8 & $0.04 \pm 0.05$ & a \\
\hline Streams & 11 & $60.48 \pm 39.7$ & $\mathrm{~b}$ & $0.03 \pm 0.02$ & $\mathrm{~b}$ & 79 & $3.25 \pm 4.07$ & $\mathrm{~b}$ \\
\hline \multirow[t]{3}{*}{ Kruskal-Wallis } & & $\chi^{2}=21.43$ & & $\chi^{2}=15.40$ & & & $\chi^{2}=47.77$ & \\
\hline & & $p<0.01$ & & $p<0.01$ & & & $p<0.01$ & \\
\hline & & $\eta^{2}=0.65$ & & $\eta^{2}=0.45$ & & & $\eta^{2}=0.20$ & \\
\hline \multicolumn{9}{|l|}{ Semi-labile } \\
\hline Bioassays & 32 & $0.05 \pm 0.20$ & a & $82.6 \pm 173.01$ & a & 19 & $0.02 \pm 0.02$ & a \\
\hline Experimental streams & 5 & $0.04 \pm 0.21$ & a & $-1.77 \pm 9.93$ & a & 5 & $0.01 \pm 0.01$ & a \\
\hline Streams & 14 & $0.32 \pm 0.23$ & $\mathrm{~b}$ & $4.99 \pm 5.56$ & a & 15 & $0.26 \pm 0.28$ & $\mathrm{~b}$ \\
\hline \multirow[t]{3}{*}{ Kruskal-Wallis } & & $\chi^{2}=16.01$ & & $\chi^{2}=16.75$ & & & $\chi^{2}=16.75$ & \\
\hline & & $p<0.01$ & & $p<0.01$ & & & $p<0.01$ & \\
\hline & & $\eta^{2}=0.29$ & & $\eta^{2}=0.35$ & & & $\eta^{2}=0.69$ & \\
\hline
\end{tabular}


incubated in bioassays, but mean labile DOC half-lives for experimental streams $(1.26 \mathrm{~d} \pm 1.9)$ were more similar to real streams $(0.03 \mathrm{~d} \pm 0.02)$ than to bioassays (4.82 $\mathrm{d} \pm 5.91)$.

\section{Confirmation of assumptions needed to quantify non-additive effects}

Labile vs semi-labile decay rates To confirm that labile DOM sources (algae and light-degraded) had faster decay rates than semi-labile DOM sources (soil and plant), we tested the difference between labile and semi-labile decay rates estimated with $1^{\text {st }}$-order decay from single-source incubations. Mean DOC decay rates of light vs dark treatments of experimental streams were not different after 6 h (HDI: $-2.61,3.96), 24 \mathrm{~h}(-0.99,0.45)$, or $70 \mathrm{~h}(-0.38$, 0.23; Fig. S4). Therefore, we assessed decay rates among treatments for all 8 streams combined.

Differences in labile and semi-labile DOM sources were always greatest within the first 6 to $24 \mathrm{~h}$ of single-source incubations (Tables 2, S5). For example, algal DOC decay rates were always at least $2 \times$ faster than soil and plant DOC decay rates in both bottles and experimental streams, except after $70 \mathrm{~h}$, when algal decay rates were slower in experimental streams (Tables 2, S5). Light-degraded plant DOC decay rates were faster than soil and plant decay rates over the first $6 \mathrm{~h}$ of incubations in both bottles and experimental streams but were not different after 24 and $70 \mathrm{~h}$.

\section{DOM composition and lability characterized by fluorescence}

We calculated fluorescence indices to characterize DOM from different leachates as labile or semi-labile and to identify changes in DOM composition due to exposure to sunlight or differences in light and dark treatments across all incubations. We compared fluorescence indices from the last time-point $(70 \mathrm{~h})$ of each incubation because that is when differences among leachate DOM composition were greatest. Bayes factors indicated that leachate source explained the most variation in BIX, HIX, and TC fluorescence metrics, while FI and SUVA values were best explained by the interaction of leachate source and light vs dark experimental stream treatment (Table S6). The FI values were greater in light experimental streams (mean: $1.65 \pm 0.09 \mathrm{SD})$ than dark experimental streams $(1.61 \pm$ 0.09 ) indicating more microbially-derived DOM in light streams (Fig. 3, Table S6). SUVA and HIX values were lower in the SoilLight (SUVA mean: $2.44 \pm 0.23$ SD; HIX: $4.94 \pm$ 0.68 ) incubation than the soil incubation (SUVA: $2.7 \pm 0.23$; HIX: $6.20 \pm 0.26$ ), indicating a decrease in aromatic content of soil-derived DOM after exposure to sunlight (Fig. S7, Table S6). Likewise, indices of recently derived DOM (BIX) and protein-like DOM (TC) were greater in the SoilLight (BIX: $0.76 \pm 0.02$; TC: $0.57 \pm 0.09$ ) than soil incubation (BIX: $0.70 \pm 0.01$; TC: $0.46 \pm 0.03$; Fig. S7, Table S6). SUVA values indicated plant DOM had lower aromatic content (mean: $0.63 \pm 0.19)$ than algal $(3.02 \pm 2.9)$ and soil-derived $\operatorname{DOM}(2.6 \pm 0.29$; Fig. 3).

To identify major fluorophores, we resolved a 5component PARAFAC model (hereafter $\mathrm{C} 1-\mathrm{C} 5$ ) and validated it with split-half analysis (Fig. S8). C1 through C5 were at least $95 \%$ identical to fluorophores identified within the OpenFluor library (Murphy et al. 2014). C1, C2, and C3 were described as humic-like in previous studies and this study (Table 3). Earlier studies described C4 as recently or microbially derived (Murphy et al. 2013). In this study, \% C4 was greatest for plant-derived DOM (Fig. 4), which had less aromatic content (i.e., lower SUVA values) than soil DOM (Fig. 3). Also, plant-derived DOM was more recently derived than soil DOM, as indicated by greater BIX values

Table 2. Single-source dissolved organic carbon (DOC) decay rates $(1 / \mathrm{d})$ calculated after 6,24 , and $70 \mathrm{~h}$ using $1^{\text {st }}$-order decay models in bottle bioassays and experimental streams. Leachates were made by mixing groundwater with algae, soil, or roasted barley (Plant) and filtering leachates through $0.2-\mu \mathrm{m}$ filters. Labile leachates included algal, light-degraded soil (SoilLight) and light-degraded plant leachate (PlantLight). Values are reported with the mean $(n=8) \pm$ standard deviation. Positive values represent decay, and negative values indicate no decay or DOC production.

\begin{tabular}{lcccrr}
\hline Incubation time period & Algae & Soil & SoilLight & Plant & PlantLight \\
\hline Bottles & & & & & \\
Decay rate after 6 h & $1.17 \pm 0.64$ & $0.53 \pm 0.3$ & $0.06 \pm 0.36$ & $-0.72 \pm 0.45$ & $1.31 \pm 0.95$ \\
Decay rate after 24 h & $0.27 \pm 0.09$ & $0.13 \pm 0.03$ & $0.20 \pm 0.04$ & $0.10 \pm 0.18$ & $-0.09 \pm 0.08$ \\
Decay rate after 70 h & $0.09 \pm 0.03$ & $<0.01 \pm 0.03$ & $0.07 \pm 0.01$ & $0.05 \pm 0.04$ & $<0.01 \pm 0.03$ \\
Mean of 3 time periods & 0.51 & 0.22 & 0.11 & -0.19 & 0.41 \\
Experimental streams & & & & $0.21 \pm 0.07$ & $1.54 \pm 0.74$ \\
Decay rate after 6 h & $2.06 \pm 0.66$ & $-0.32 \pm 0.26$ & $0.25 \pm 0.17$ & $-0.12 \pm 0.02$ & $-0.32 \pm 0.26$ \\
Decay rate after 24 h & $0.39 \pm 0.13$ & $-0.02 \pm 0.04$ & $-0.27 \pm 0.35$ & $0.25 \pm 0.02$ & $0.23 \pm 0.02$ \\
Decay rate after 70 h & $0.23 \pm 0.06$ & $-0.04 \pm 0.02$ & $0.20 \pm 0.08$ & 0.19 & 0.48 \\
Mean of 3 time periods & 0.89 & -0.13 & 0.06 & & \\
\hline
\end{tabular}




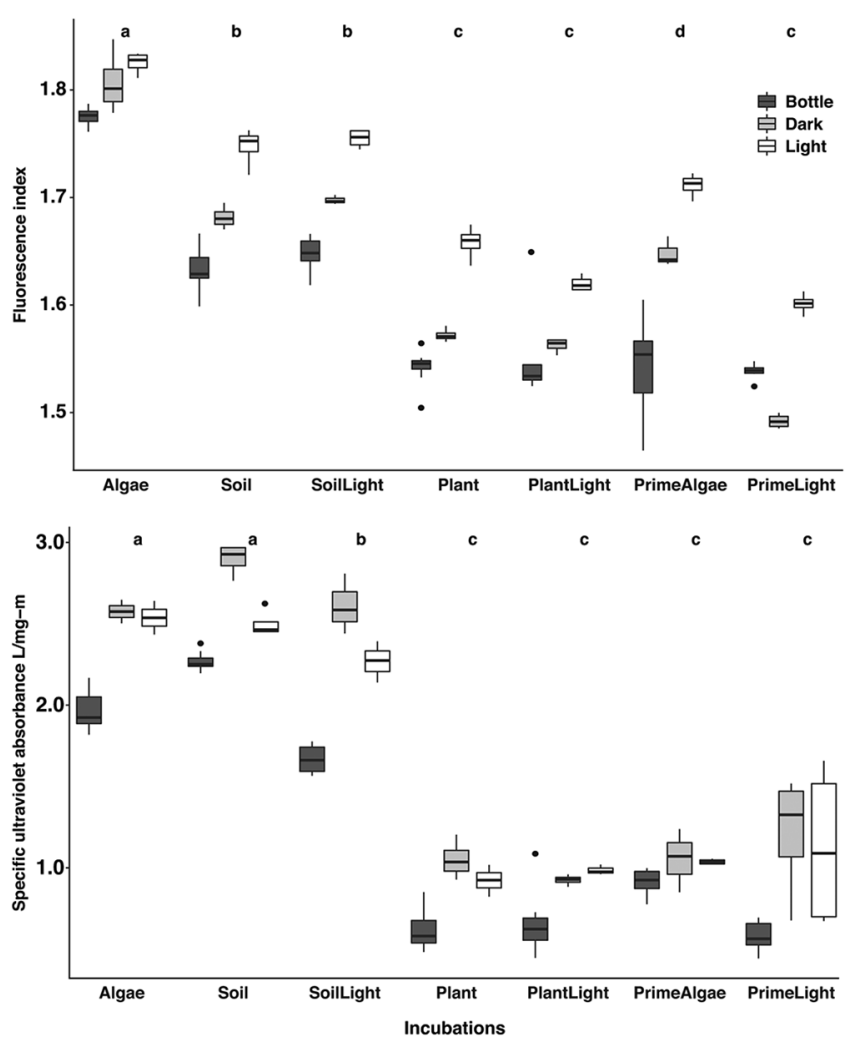

Figure 3. Comparison of fluorescence index (FI) and specific ultraviolet absorbance at $254 \mathrm{~nm}$ (SUVA) values between bottle bioassays (black boxes, $n=8$ ), dark experimental streams (gray boxes, $n=4$ ), and light experimental streams (open boxes, $n=4$ ) among single-source and non-additive effects incubations. Singlesource incubations were conducted first with algal, soil, lightdegraded soil (SoilLight), plant, and light-degraded plant (PlantLight) leachates, followed by non-additive effects incubations where plant leachate was mixed with algal leachate (PrimeAlgae) or light-degraded plant leachate (PrimeLight). Boxes represent the median and interquartile range, whiskers represent the 2.5 to 97.5 percentile range, and dots are outliers. Letters indicate mean FI and SUVA values that differed based on Tukey honestly significant difference multiple comparison of means.

(Fig. S7). C5 was protein-derived, tryptophan-like DOM in both this and previous studies (Coble 1996, Yamashita and Tanoue 2003; Table 3).

Bayes factors were greatest for linear models that only included leachate source as an explanatory variable, indicating leachate source (e.g., algae, soil, plant) best described variation in \% PARAFAC components regardless of incubation in bottles vs experimental streams or light vs dark treatments (Table S6). However, for C2, the linear model that included the explanatory variables of dark vs light experimental streams, bottle vs stream, and the interaction of the 2 variables had the highest Bayes factor which was 3 orders of magnitude higher than the $2^{\text {nd }}$-highest Bayes factor (Table S6). Percent C2 was lower in light streams at the end of all incubations, except the algae incubation, indicating C2 was susceptible to light degradation (Fig. 4). The greatest concentrations of C3 were in the soil and SoilLight incubations (range: 23-29\%) and were associated with older humic DOM because C3 was positively correlated with the HIX and SUVA ( $r=0.64$ and 0.75, respectively; Fig. S9). C3 appeared to be produced from light exposure because it increased in proportion to other components in the light streams of all plant incubations (Fig. 4). C3 in plant incubations appeared to be the inverse of $\mathrm{C} 2$, but there is no way to know if the inverse relationship represents a transformation of $\mathrm{C} 2$ to $\mathrm{C} 3$ through microbial activity or is a result of mathematically constraining fluorophores to 5 components. C4 had highest concentrations in plant incubations (range: 24-31\%) and was negatively correlated with the HIX and SUVA ( $r=-0.72$ and -0.81 , respectively; Fig. S9). C5, the protein-like component, declined in all incubations except for the soil incubation, which had the lowest \% protein out of all incubations (range: 10-16\%).

Benthic biomass We did not detect differences across incubations in benthic biomass measured as AFDM, which confirmed that biomass was not a factor in differences in decay rates among incubations (1-way ANOVA, $F_{6,48}, \eta^{2}=$ $0.09, p=0.56$; Fig. S10). Chl $a$ concentrations normalized to cobble area were higher in soil leachate incubations compared to all other leachate incubations (1-way ANOVA, $F_{6,48}, \eta^{2}=0.38, p<0.01$; Fig. S10).

\section{Quantification of non-additive effects}

Non-additive effects in bioassays Variation in singlesource estimates of plant leachate decay in bottles was extremely high (CV mean: 111\%) compared to experimental streams (20\%; Table 2, Fig. S1). Therefore, we could not calculate meaningful effect sizes for non-additive effects in bottles, and we do not discuss such effects further.

Algal plus plant leachate non-additive effects The 2 models we used to quantify non-additive effects produced inconsistent estimates of non-additive effects when algal and plant leachates were mixed (PrimeAlgae). The biexponential models estimated negative non-additive effects on semi-labile DOC decay, whereas the biphasic model estimated a range of negative to positive non-additive effects (Table 4). The PrimeAlgae biphasic model had a better fit than the biexponential model, as indicated by regressions between predicted and modeled DOC concentration (Table 4). A positive non-additive effect was detected with the biphasic model, but the median effect size was very small $(0.032 / d)$ and unconstrained, as demonstrated by a wide-ranging HDI that included values an order of magnitude greater than the median effect size (HDI: -0.041-0.134). Wide-ranging effect sizes 
Table 3. Descriptions of 5 components $(\mathrm{C} 1-\mathrm{C} 5)$ identified by PARAFAC and had a Tucker's congruence coefficient $>0.95$ with components in the OpenFluor library (Murphy et al. 2014). Excitation (EX) and emission (EM) wavelengths are the unique wavelength where the corresponding component had maximum fluorescence intensity. Humic-like components are considered semi-labile, whereas recently-derived, microbially-derived, protein-like, and tryptophan-like components are considered labile sources of DOM.

\begin{tabular}{|c|c|c|c|c|c|}
\hline Component & $\mathrm{EX}(\mathrm{nm})$ & $\mathrm{EM}(\mathrm{nm})$ & References & Reference description & Our description \\
\hline $\mathrm{C} 1$ & 340 & $435-440$ & Osburn et al. 2011 & Humic-like & Humic-like \\
\hline $\mathrm{C} 2$ & $255-260$ & $495-500$ & $\begin{array}{l}\text { Stedmon and Markager 2005, } \\
\text { Yamashita et al. } 2008\end{array}$ & Humic-like & $\begin{array}{l}\text { Humic-like, susceptible to } \\
\text { light degradation }\end{array}$ \\
\hline C3 & 248 & $430-440$ & $\begin{array}{l}\text { Shutova et al. } 2014 \\
\text { Osburn et al. } 2016\end{array}$ & Humic-like & $\begin{array}{l}\text { Humic-like, product of } \\
\text { light degradation }\end{array}$ \\
\hline $\mathrm{C} 4$ & 315 & $385-390$ & $\begin{array}{l}\text { Osburn et al. 2011, } \\
\text { Shutova et al. } 2014\end{array}$ & $\begin{array}{l}\text { Recently derived or } \\
\text { microbially-derived }\end{array}$ & Recently derived, terrestrial \\
\hline C5 & 278 & $330-335$ & $\begin{array}{l}\text { Coble 1996, Yamashita } \\
\text { and Tanoue } 2003\end{array}$ & Protein-like, tryptophan-like & Protein-like \\
\hline
\end{tabular}

may have been due to difficulty in estimating decay rates of the labile DOM pool in some streams. For example, biexponential estimates of $k_{\text {fast }}$ for algal leachate were slower (mean: $0.12 / \mathrm{d} \pm 0.05 \mathrm{SD}$ after $70 \mathrm{~h}$ ) than estimates of $k_{\text {slow }}$ (mean: $2.55 / \mathrm{d} \pm 2.14 \mathrm{SD}$ after $70 \mathrm{~h}$ ).
Light-degraded plant plus plant leachate non-additive effects In the PrimeLight incubation, the 6-h biexponential model and the biphasic model both predicted a positive nonadditive effect of light-degraded plant DOM on plant leachate (Table 4). The 6-h biexponential model had the greatest

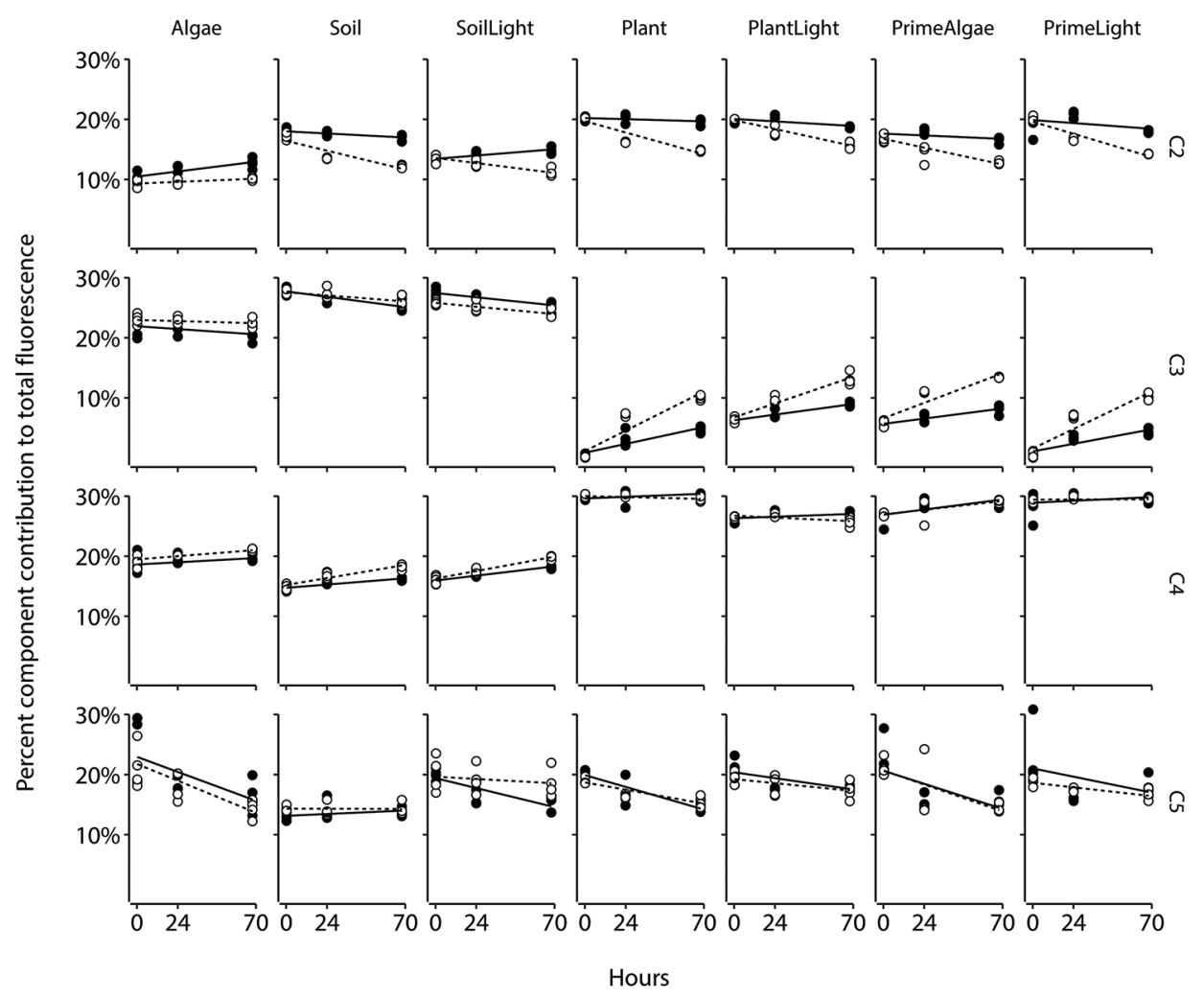

Figure 4. Percent fluorescence contribution for components 2 through $5(\mathrm{C} 2, \mathrm{C} 3, \mathrm{C} 4, \mathrm{C} 5)$ after 1, 24, and 70 h. Black lines and circles represent streams covered to exclude sunlight (dark streams; $n=4$ ); dashed lines and white circles represent streams left uncovered (light streams; $n=4$ ). C1 was humic-like and did not change over the course of each incubation (not shown). C2 and C3 were humic-like, C4 was recently-derived humic-like, and C5 was protein-like (Table 3). 
Table 4. Estimated mean and standard deviation of decay rates $(1 / \mathrm{d})$ for the labile $\left(k_{\text {fast }}\right)$ and semi-labile $\left(k_{\text {slow }}\right)$ pools of DOM in the PrimeAlgae and PrimeLight incubation at 6, 24, and $70 \mathrm{~h}$. Biexponential models were fit with Eq. $4\left(C_{\mathrm{t}}=p_{1} C_{1\left(t_{0}\right)} e^{-k_{\text {fast }} t}+p_{2} C_{2\left(t_{0}\right)} e^{-k_{\text {slow }} t}\right)$ and biphasic models were fit with Eq. $5\left(C_{t^{*}}=C_{0} e^{-k_{\text {fast }} t}\right)$ and Eq. $6\left(C_{\mathrm{t}}=C_{0} e^{-k_{\text {fast }} t_{*}} e^{-k_{\text {slow }} t-t_{*}}\right)$, where $C_{0}$ and $C_{\mathrm{t}}$ represent DOC concentrations of both labile $\left(C_{1}\right)$ and semi-labile $\left(C_{2}\right)$ pools at the start and end of the period, $t$ represents time, $t^{*}$ represents a breakpoint, and $p_{1}$ and $p_{2}$ are the proportional volumes of each leachate. Model fit was assessed through linear regression of measured vs modeled final DOC concentrations. The highest density interval (HDI) of effect size was calculated as the difference in the HDI of the posterior probability distribution of $k_{\text {slow }}$ and single-source estimates of plant decay $k_{\text {tot }}$ where a positive median effect size indicated a positive non-additive (priming) effect.

\begin{tabular}{|c|c|c|c|c|c|c|c|c|}
\hline \multirow[b]{2}{*}{ Incubation type } & \multirow[b]{2}{*}{ Model } & \multirow{2}{*}{$\begin{array}{c}t \\
(\mathrm{~h})\end{array}$} & \multirow{2}{*}{$\begin{array}{c}k_{\text {slow }} \\
\text { mean }(1 / d)\end{array}$} & \multirow{2}{*}{$\begin{array}{c}k_{\text {fast }} \\
\text { mean }(1 / d)\end{array}$} & \multirow{2}{*}{$\begin{array}{l}\text { Model fit } \\
\text { slope, } r^{2}\end{array}$} & \multicolumn{3}{|c|}{ Effect size } \\
\hline & & & & & & $2.5 \%$ & $50 \%$ & $97.5 \%$ \\
\hline \multirow[t]{4}{*}{ PrimeAlgae } & Biexponential & 6 & $1.25,2.88$ & $-1.23,0.31$ & $0.36,0.94$ & -1.835 & -1.459 & -0.887 \\
\hline & Biexponential & 24 & $1.73,1.89$ & $0.06,0.15$ & $0.11,0.61$ & -0.258 & -0.068 & 0.235 \\
\hline & Biexponential & 70 & $2.55,2.14$ & $0.12,0.05$ & $0.13,0.95$ & -0.180 & -0.136 & -0.037 \\
\hline & Biphasic & 70 & fixed $=0.31^{\mathrm{a}}$ & $0.28,0.06$ & $0.43,0.88$ & -0.041 & 0.032 & 0.134 \\
\hline \multirow[t]{3}{*}{ PrimeLight } & Biexponential & 6 & $3.19,2.67$ & $5.37,2.18$ & $0.20,0.56$ & 1.655 & 4.931 & 9.871 \\
\hline & Biexponential & 24 & $2.68,2.32$ & $4.52,3.96$ & $0.42,0.13$ & -4.252 & 4.634 & 11.702 \\
\hline & Biphasic & 24 & fixed $=2.0^{\mathrm{b}}$ & $1.05,0.96$ & $0.55,0.83$ & -0.764 & 0.880 & 2.990 \\
\hline
\end{tabular}

${ }^{\mathrm{a}} k_{\text {fast }}$ was fixed at $0.31 / \mathrm{d}$, which was estimated from time 0 to the breakpoint at $0.5 \mathrm{~d}$ with Eq. 5.

${ }^{\mathrm{b}} k_{\text {fast }}$ was fixed at $2.0 / \mathrm{d}$, which was estimated from time 0 to the breakpoint at $0.25 \mathrm{~d}$ with Eq. 5 .

median effect size of 4.93/d (HDI: 1.65, 9.87). However, despite a positive median effect size, biexponential model estimates of both fast and slow decay rates were highly variable (CV mean: 123\%). The biphasic model also had a large effect size, but effect size estimates were wide ranging as indicated by the broad posterior probability density around the median of 0.88/d (HDI: $-0.76,2.99)$.

\section{DISCUSSION}

Our $1^{\text {st }}$ goal was to quantify DOM decay in bioassays and experimental streams to put laboratory estimates of decay in context with real streams. BDOC was lower in bioassays compared to experimental streams in this study, but other metrics of DOM demand, such as decay rates, half-lives, and uptake velocities, were lower in bioassays and experimental streams compared to real streams. Our $2^{\text {nd }}$ goal was to quantify non-additive effects in bioassays and experimental streams when labile and semi-labile sources of DOM were mixed. We found the magnitude of non-additive effects depended on the length of time over which decay rates were calculated, suggesting DOM decay rates were not constant over time. Therefore, models that assume a constant decay rate (e.g., $1^{\text {st }}$-order decay) may not be the best models to describe DOM demand in streams, especially over short time periods (i.e., $<3 \mathrm{~d}$ ).

\section{Bioassays and experimental streams may underestimate DOC demand in real streams}

Mean BDOC in experimental streams was $2 \times$ greater than in bottle bioassays in this study, which suggests bioassays underestimated DOC demand compared to experimental streams. Experimental stream BDOC in this study (mean: $52.6 \% \pm 20.3 \mathrm{SD}$ ) was greater than BDOC measured in bioassays for large rivers in the midwestern and western US (8.8\% \pm 4.6 ; Hotchkiss et al. 2014) and headwater streams of the Maryland Coastal Plain (0-25\%; Hosen et al. 2014) but similar to previous estimates of $\%$ DOC consumed at the watershed scale, which ranged from 27 to $45 \%$ for 7 watersheds in the northeastern region of the US (Mineau et al. 2016). Thus, the BDOC metric suggests bioassays underestimate DOC demand not only in experimental streams, but also in real streams.

Other metrics of DOC loss, such as decay rates and uptake velocities of DOC, were greater in real streams compared to both bioassays and experimental streams. Many field studies add glucose as a proxy for the labile forms of DOM, an approach that overestimates DOC demand for the entire DOM pool (Mineau et al. 2016), which may contribute to faster estimates of DOM demand in real streams. However, semilabile sources of DOM also tended to have faster estimates of DOM demand in real streams. For naturally-occurring riverine DOM, Mineau et al. (2016) derived a scaling factor to apply bioassay decay constants to reach-scale leaf leachate additions and constrained DOC uptake velocities to a range of 0.26 to $1.5 \mathrm{~mm} / \mathrm{min}$ for rivers with average DOC concentration of $4.3 \mathrm{mg} / \mathrm{L}$. The range of uptake velocities in this study of bioassays $(-0.035-0.1 \mathrm{~mm} / \mathrm{min})$ and experimental streams $(-0.016-0.131 \mathrm{~mm} / \mathrm{min})$ were both lower than the minimum $0.26 \mathrm{~mm} / \mathrm{min}$ reported by Mineau et al. (2016), implying both bioassays and experimental streams underestimate DOM demand in real streams.

Bioassays may underestimate decay because they exclude DOC consumption by benthic biofilms and the effect of abiotic factors, such as photodegradation, adsorption, and sedimentation (Cory and Kaplan 2012, Catalán et al. 2016). Field 
studies better integrate all processes of DOC loss and production, which may have minimal consequences for bioassays of aquatic systems with long water residence times (e.g., $>1$ y) but could significantly influence bioassay decay rates in water bodies with short residence times, such as streams (Catalán et al. 2016). Field studies of OM demand through mass balance models of organic carbon flux can account for instream processes such as benthic uptake, hyporheic flow, and photodegradation (Catalán et al. 2016, Mineau et al. 2016). Although mass balance models may better reflect realistic conditions for DOC processing, they also result in highlyvariable estimates of bulk DOC demand ranging from 0.03 to $430.8 \mathrm{~mm} / \mathrm{min}$ (Thomas et al. 2005, Griffiths et al. 2012, Epstein et al. 2016, Hall et al. 2016). Further study is needed to understand if experimental streams or similarly-sized mesocosms can fill the gap in estimating DOM demand in real streams. We found that although BDOC estimated from experimental streams was similar to 1 other study that estimated BDOC at the watershed scale (Mineau et al. 2016), DOM demand metrics were lower in experimental streams compared to real streams. Our experimental streams accounted for additional DOM demand processes associated with the benthic zone; however, further studies are needed to test the ability of experimental streams to account for larger-scale processes associated with hyporheic exchange and abiotic controls on DOM transformations that we could not control for, such as temperature.

\section{Light increased BDOC of soil leachate}

Exposure to natural sunlight decreased aromatic content in DOM and increased BDOC of light-degraded soil compared to the single-source soil incubations in experimental streams. Our indices of DOM degradation by natural sunlight differed from previous studies because sunlight exposure time was much shorter than previous incubations. One other study, conducted in streams, found significant changes in tyrosine-like DOM within 4 to $7 \mathrm{~h}$ of sunlight exposure (Cory et al. 2007), but most studies investigated the effect of light over 24 to $48 \mathrm{~h}$ (Skully et al. 2004, Bittar et al. 2015) or up to 5 wk (Guillemette and del Giorgio 2011, Catalán et al. 2015). Our study highlights the effect of sunlight on DOM quality after just 3 to $4 \mathrm{~h}$ of exposure, a duration that represented the minimum duration of sunlight exposure for a stream in the warm months of a temperate ecosystem with some riparian shade and a short travel time (e.g., 20 h; Epstein et al. 2016). Therefore, photodegradation may be an important factor that influences DOM decay in streams even at hourly timescales (Bowen et al. 2019).

\section{Decay rates of labile and semi-labile DOM pools were difficult to distinguish and quantify}

Neither biexponential nor biphasic decay models could constrain estimates of the labile and semi-labile pools for non-additive effects incubations. Therefore, neither posi- tive nor negative non-additive effects were consistently quantified. Positive non-additive effects were detected in the PrimeLight incubation, but wide-ranging estimates of single-source decay rates resulted in a wide range in effect sizes. For example, the PrimeLight biexponential model estimated an effect size ranging from -4.2 /d to $11.7 / \mathrm{d}$ suggesting non-additive effects could be either positive or negative. Non-additive effects were always negative for the PrimeAlgae biexponential model because the model could not distinguish between the labile and semi-labile DOM pool, as indicated by the model estimating a faster decay rate for the slow compared to fast pool.

A stable isotope tracer of terrestrially-derived DOM would have helped differentiate fast and slow pools, allowing better estimation of labile and semi-labile decay rates. Several studies have used $\delta^{13} \mathrm{C}$ stable isotope tracers of the labile (van Nugteren et al. 2009, Gontikaki et al. 2013, Guenet et al. 2014, Bianchi et al. 2015, Trevathan-Tackett et al. 2018) and semi-labile (Bengtsson et al. 2014, Ward et al. 2016, Wagner et al. 2017, Gontikaki and Witte 2019) DOM pools, whereas others used ${ }^{14} \mathrm{C}$-labeled semi-labile DOM (Steen et al. 2016). However, for most of these studies, the effect size was also highly variable (Bengtsson et al. 2018), and evidence to confirm positive non-additive effects was lacking. For example, studies in rivers and streams reported effect sizes ranging from -90 to $150 \%$ change in semi-labile pool degradation (Bengtsson et al. 2014, Ward et al. 2016, Wagner et al. 2017).

Additionally, it was hard to quantify net DOM decay because, similar to previous bioassay incubations, DOC concentrations increased during the initial phase of incubations (Hosen et al. 2014, Bianchi et al. 2015). All but 2 incubations in this study included DOM production after incubation in the dark, resulting in highly-variable decay rates that may have underestimated the total amount of DOM assimilated or mineralized. We recommend future bioassay studies account for production with ambient DOC controls (e.g., Hosen et al. 2014, Textor et al. 2018), which may reduce variation in estimates of single-source decay.

\section{Quantification of non-additive effects depends on incubation period}

In this study, decay rates were faster when calculated within the first 6 to $24 \mathrm{~h}$ of the incubation compared to $70 \mathrm{~h}$ for both bioassays and experimental streams, which violates the assumption of a constant decay rate for $1^{\text {st }}$-order decay models. Most DOM decay studies assume a constant $1^{\text {st }}$ order decay rate (Guillemette et al. 2013), but most studies also conduct incubations for longer than $3 \mathrm{~d}$. A few studies have estimated DOM decay within the first 12 to $24 \mathrm{~h}$ of incubation (Cory et al. 2007, Lyon and Zeigler 2009, Ward et al. 2016), but most incubation durations range over days (Bernhardt and Likens 2002, Hotchkiss et al. 2014), weeks (Guillemette and del Giorgio 2011, Catalán et al. 2015), 
months (Danger et al. 2013), and years (Vähätalo and Wetzel 2008, Evans et al. 2017). Labile DOM pools in freshwater are known to decay within minutes (Pollard 2013, Bowen et al. 2019) or within hours to $1 \mathrm{~d}$ (Guillemette and del Giorgio 2011, Cory and Kaplan 2012, Hotchkiss et al. 2014, Mostovaya et al. 2016), while semi-labile DOM is assumed to decay over weeks or months (del Giorgio and Pace 2008, Guillemette and del Giorgio 2011). Perhaps the inconstant decay rate in our study was an artifact of the very short incubation time, and $1^{\text {st }}$-order decay models are most appropriate for experiments with longer incubation periods (weeksmonths) vs short incubation periods (hours-days). Future studies should consider alternatives to $1^{\text {st }}$-order decay models, such as the reactivity continuum model (Koehler et al. 2012, Guillemette et al. 2013) and the 3-parameter reactivity exponential decay model (Textor et al. 2018), which do not assume a constant decay rate and, therefore, may better characterize DOM degradation in real streams.

Future studies using bioassays to quantify consumption of autochthonous DOM, or other labile DOM sources, should also consider the water residence time of the ecosystem the bioassay represents. For example, to account for degradation of the most labile forms of organic matter in streams, we recommend bioassays include sampling within the first 24 to $48 \mathrm{~h}$ of incubations. Improved estimates of labile DOM consumption rates at finer timescales (e.g., hours) can help clarify assumptions needed to model organic carbon flux in water bodies with short residence times, especially streams.

\section{Positive non-additive effects remain elusive in aquatic ecosystems}

The study of non-additive effects of labile and semi-labile DOM in aquatic ecosystems has received renewed attention in the last decade (Guenet et al. 2010, Bengtsson et al. 2018), but overall evidence for positive non-additive effects in aquatic ecosystems remains lacking (Bengtsson et al. 2018, Textor et al. 2018). We acknowledge that the inability to detect consistent positive non-additive effects could reflect that priming does not occur in aquatic ecosystems. We propose that quantification of positive non-additive effects will continue to remain elusive because of inconsistencies in the timescale over which priming is defined and high variability in the chemical compounds and methods used to simulate the decay of labile and semi-labile OM pools. Since 2010, 20 studies explicitly tested for non-additive effects of DOM in aquatic ecosystems, 8 measured a positive non-additive effect, 7 did not measure positive non-additive effects, and 5 measured both positive and negative non-additive effects (Bengtsson et al. 2018 and references within, Textor et al. 2018, Gontikaki and Witte 2019). Of studies that identified positive nonadditive effects, 3 measured DOM demand within the first $3 \mathrm{~d}$ of incubations and noted that maximum rates of DOM demand occurred within the first $24 \mathrm{~h}$ of incubation (Guenet et al. 2014, Bianchi et al. 2015, Ward et al. 2016). Of recent non-additive effect studies, $65 \%$ used naturally-occurring labile OM, such as algal leachates, while the other studies used glucose or other simple compounds that likely overestimate the DOM demand within the labile DOM pool (Bengtsson et al.2018). It is also important to consider the timescale over which non-additive effects are quantified because increased rates of DOC loss in the short term (hours-days) may only account for microbial biomass accrual and turnover (i.e., apparent priming) and not represent actual increased rates of semi-labile OM mineralization (Textor et al. 2018). This study fills gaps identified by previous investigations of nonadditive effects in aquatic ecosystems because we estimated DOM decay within the first $24 \mathrm{~h}$ of incubation, used natural sources of labile DOM, and included a benthic component in estimation of DOM decay.

\section{ACKNOWLEDGEMENTS}

Author contributions: JK designed the experiment, collected and analyzed the data, and wrote the manuscript. ER designed the experiment and provided substantive comments and revisions on the manuscript. MB designed the experiment and wrote the manuscript.

We would like to thank the scientists and staff of the Cary Institute of Ecosystem Studies for their help at the Artificial Stream Facility as well as Lindsay Capito, Autumn Slade, and Dave Epstein for their help in the laboratory. The manuscript was improved by thoughtful comments from Zachary Aanderud, Bethany Neilson, John Stark, Matt Miller, and 2 anonymous reviewers. We thank our funders at Utah State University, including the School of Graduate Studies, Department of Biology, and Ecology Center. This research was also supported by the National Science Foundation (awards IIA 12-08732 and DEB 17-54216).

\section{LITERATURE CITED}

Baker, A. 2001. Fluorescence excitation-emission matrix characterization of some sewage-impacted rivers. Environmental Science \& Technology 35:948-953.

Battin, T. J., L. A. Kaplan, S. Findlay, C. S. Hopkinson, E. Marti, A. I. Packman, J. D. Newbold, and F. Sabater. 2009. Biophysical controls on organic carbon fluxes in fluvial networks. Nature Geoscience 1:95-100.

Bengtsson, M. M., K. Attermeyer, and N. Catalán. 2018. Interactive effects on organic matter processing from soils to the ocean: Are priming effects relevant in aquatic ecosystems? Hydrobiologia 822:1-17.

Bengtsson, M. M., K. Wagner, N. R. Burns, E. R. Herberg, W. Wanek, L. A. Kaplan, and T. J. Battin. 2014. No evidence of aquatic priming effects in hyporheic zone microcosms. Scientific Reports 4:5187.

Bernhardt, E. S., and G. E. Likens. 2002. Dissolved organic carbon enrichment alters nitrogen dynamics in a forest stream. Ecology 83:1689-1700.

Bianchi, T. S., D. C. Thornton, S. A. Yvon-Lewis, G. M. King, T. I. Eglinton, M. R. Shields, N. D. Ward, and J. Curtis. 2015. Positive priming of terrestrially derived dissolved organic matter in a freshwater microcosm system. Geophysical Research Letters 42:5460-5467. 
Bittar, T. B., A. A. H. Vieira, A. Stubbins, K. Mopper. 2015. Competition between photochemical and biological degradation of dissolved organic matter from the cyanobacteria Microcystis aeruginosa. Limnology and Oceanography 60:1172-1194.

Bowen, J. C., L. A. Kaplan, and R. M. Cory. 2019. Photodegradation disproportionately impacts biodegradation of semi-labile DOM in streams. Limnology and Oceanography 65:13-26.

Brouwer, A. F., M. C. Eisenberg, J. V. Remais, P. A. Collender, R. Meza, and J. N. Eisenberg. 2017. Modeling biphasic environmental decay of pathogens and implications for risk analysis. Environmental Science \& Technology 51:2186-2196.

Butman, D., S. Stackpoole, E. Stets, C. P. McDonald, D. W. Clow, and R. G. Striegl. 2016. Aquatic carbon cycling in the conterminous United States and implications for terrestrial carbon accounting. Proceedings of the National Academy of Sciences 113:58-63.

Catalán, N., J. P. Casas-Ruiz, M. I. Arce, M. Abril., A. G. Bravo, R. del Campo, E. Estévez, A. Freixa, P. Giménez-Grau, A. M. GonzálezFerreras, L. I. Gómez-Gener, A. Lupon, A. Martínez, C. PalacinLizarbe, S. Poblador, R. Rasines-Ladero, M. Reyes, T. RodríguezCastillo, P. Rodríguez-Lozano, I. Sanpera-Calbet, I. Tornero, and A. Pastor. 2018. Behind the scenes: Mechanisms regulating climatic patterns of dissolved organic carbon uptake in headwater streams. Global Biogeochemical Cycles 32:1528-1541.

Catalán, N., A. M. Kellerman, H. Peter, F. Carmona Pontaque, and L. J. Tranvik. 2015. Absence of a priming effect on dissolved organic carbon degradation in lake water. Limnology and Oceanography 60:159-168.

Catalán, N., R. Marcé, D. N. Kothawala, and L. J. Tranvik. 2016. Organic carbon decomposition rates controlled by water retention time across inland waters. Nature Geoscience 9:501-504.

Chen, M., and R. Jaffé. 2014. Photo- and bio-reactivity patterns of dissolved organic matter from biomass and soil leachates and surface waters in a subtropical wetland. Water Research 61:181190.

Coble, P. G. 1996. Characterization of marine and terrestrial DOM in seawater using excitation-emission matrix spectroscopy. Marine Chemistry 51:325-346.

Cohen, J. 1988. Statistical power analysis for the behavioral sciences. $2^{\text {nd }}$ edition. Lawrence Erlbaum Associates, Hillsdale, New Jersey.

Cory, R. M., and L. A. Kaplan. 2012. Biological lability of streamwater fluorescent dissolved organic matter. Limnology and Oceanography 57:1347-1360.

Cory, R. M., and D. M. McKnight. 2005. Fluorescence spectroscopy reveals ubiquitous presence of oxidized and reduced quinones in dissolved organic matter. Environmental Science \& Technology 39:8142-8149.

Cory, R. M., D. M. McKnight, Y. P. Chin, P. Miller, and C. L. Jaros. 2007. Chemical characteristics of fulvic acids from Arctic surface waters: Microbial contributions and photochemical transformations. Journal of Geophysical Research: Biogeosciences 112:G04S51.

Danger, M., J. Cornut, E. Chauvet, P. Chavez, A. Elger, and A. Lecerf. 2013. Benthic algae stimulate leaf litter decomposition in detritus-based headwater streams: A case of aquatic priming effect? Ecology 94:1604-1613.

Drake, T. W., P. A. Raymond, and R. G. M. Spencer. 2018. Terrestrial carbon inputs to inland waters: A current synthesis of esti- mates and uncertainty. Limnology and Oceanography 3:132142.

Eichmiller, J. J., S. A. E. Best, and P. W. Sorensen. 2016. Effects of temperature and trophic state on degradation of environmental DNA in lake water. Environmental Science \& Technology 50:1859-1867.

Epstein, D. M., J. E. Kelso, and M. A. Baker. 2016. Beyond the urban stream syndrome: Organic matter budget for diagnostics and restoration of an impaired urban river. Urban Ecosystems 19:1041-1061.

Evans, C. D., M. N. Futter, F. Moldan, S. Valinia, Z. Frogbrook, and D. N. Kothawala. 2017. Variability in organic carbon reactivity across lake residence time and trophic gradients. Nature Geoscience 10:832-835.

Fellman, J. B., D. V. D'Amore, E. Hood, and R. D. Boone. 2008. Fluorescence characteristics and biodegradability of dissolved organic matter in forest and wetland soil from coastal temperate watersheds in southeast Alaska. Biogeochemistry 88:166-184.

Findlay, S. E. G., and R. L. Sinsabaugh (editors). 2003. Aquatic ecosystems: Interactivity of dissolved organic matter. Academic Press, San Diego, California.

Gontikaki, E., B. Thornton, V. A. I. Huvenne, and U. Witte. 2013. Negative priming effect on organic matter mineralization in NE Atlantic slope sediments. PLoS ONE 8:e67722.

Gontikaki, E., and U. Witte. 2019. No strong evidence of priming effects on the degradation of terrestrial plant detritus in estuarine sediments. Frontiers in Marine Science 6:327.

Griffiths, N. A., J. L. Tank, T. V. Royer, T. J. Warrner, T. C. Frauendorf, E. J. Rosi-Marshall, and M. R. Whiles. 2012. Temporal variation in organic carbon spiraling in Midwestern agricultural streams. Biogeochemistry 108:149-169.

Guenet, B., M. Danger, L. Abbadie, and G. Lacroix. 2010. Priming effect: Bridging the gap between terrestrial and aquatic ecology. Ecology 91:2850-2861.

Guenet, B., M. Danger, L. Harrault, B. Allard, M. Jauset-Alcala, G. Bardoux, D. Benest, L. Abbadie, and G. Lacroix. 2014. Fast mineralization of land-born $\mathrm{C}$ in inland waters: First experimental evidences of aquatic priming effect. Hydrobiologia 721:35-44.

Guillemette, F., and P. A. del Giorgio. 2011. Reconstructing the various facets of dissolved organic carbon bioavailability in freshwater ecosystems. Limnology and Oceanography 56:734-748.

Guillemette, F., S. L. McCallister, and P. A. del Giorgio. 2013. Differentiating the degradation dynamics of algal and terrestrial carbon within complex natural dissolved organic carbon in temperate lakes. Journal of Geophysical Research: Biogeosciences 118:963973.

Hall, R. O., J. L. Tank, M. A. Baker, E. J. Rosi-Marshall, and E. R. Hotchkiss. 2016. Metabolism, gas exchange, and carbon spiraling in rivers. Ecosystems 19:73-86.

Halvorson, H. M., J. R. Barry, M. B. Lodato, R. H. Findlay, S. N. Francoeur, and K. A. Kuehn. 2019. Periphytic algae decouple fungal activity from leaf litter decomposition via negative priming. Functional Ecology 33:188-201.

Hosen, J. D., O. T. McDonough, C. M. Febria, and M. A. Palmer. 2014. Dissolved organic matter quality and bioavailability changes across an urbanization gradient in headwater streams. Environmental Science \& Technology 48:7817-7824.

Hotchkiss, E., R. O. Hall Jr, M. A. Baker, E. J. Rosi-Marshall, and J. L. Tank. 2014. Modeling priming effects on microbial consumption 
of dissolved organic carbon in rivers. Journal of Geophysical Research: Biogeosciences 119:982-995.

Hotchkiss, E., R. O. Hall Jr, R. A. Sponseller, D. Butman, J. Klaminder, H. Laudon, M. Rosvall, and J. Karlsson. 2015. Sources of and processes controlling $\mathrm{CO}_{2}$ emissions change with the size of streams and rivers. Nature Geoscience 8:696-699.

Kassambara, A. 2020. Pipe-friendly framework for basic statistical tests. (Available from: https://CRAN.R-project.org/package $=$ rstatix)

Koehler, B., E. Wachenfeldt, D. Kothawala, and L. J. Tranvik. 2012. Reactivity continuum of dissolved organic carbon decomposition in lake water. Journal of Geophysical Research: Biogeosciences 117:G01024.

Kruschke, J. K. 2013. Bayesian estimation supersedes the $t$ test. Journal of Experimental Psychology: General 142:573-603.

Lock, M. A., and H. B. N. Hynes. 1976. The fate of "dissolved" organic carbon derived from autumn-shade maple leaves (Acer saccharum) in a temperate hard water stream. Limnology and Oceanography 21:436-443.

Logue, J. B., C. A. Stedmon, A. M. Kellerman, N. J. Neilsen, A. F. Andersson, H. Laudon, E. S. Lindstrom, and E. S. Kertizberg. 2016. Experimental insights into the importance of aquatic bacterial community composition to the degradation of dissolved organic matter. The International Societry of Microbial Ecology Journal 10:533-545.

Lüdecke, D. 2020. Sjstats: Statistical functions for regression models. (Available from: https://CRAN.R-project.org/package $=$ sjstats)

Lyon, D. R., and S. E. Ziegler. 2009. Carbon cycling within epilithic biofilm communities across a nutrient gradient of headwater streams. Limnology and Oceanography 54:439-449.

Mineau, M. M., W. M. Wollheim, I. Buffam, S. E. Findlay, R. O. Hall Jr, E. R. Hotchkiss, L. E. Koenig, W. H. McDowell, and T. B. Parr. 2016. Dissolved organic carbon uptake in streams: A review and assessment of reach-scale measurements. Journal of Geophysical Research: Biogeosciences 121:2019-2029.

Moody, C., F. Worrall, C. Evans, and T. Jones. 2013. The rate of loss of dissolved organic carbon (DOC) through a catchment. Journal of Hydrology 492:139-150.

Moran, M. A., W. M. Sheldon, and R. G. Zepp. 2000. Carbon loss and optical property changes during long-term photochemical and biological degradataion of estuarine dissolved organic matter. Limnology and Oceanography 45:1254-1264.

Moran, M. A., and R. G. Zepp. 1997. Role of photoreactions in the formation of biologically labile compounds from dissolved organic matter. Limnology and Oceanography 42:1307-1316.

Mostovaya, A., B. Koehler, F. Guillemette, A. K. Brunberg, and L. J. Tranvik. 2016. Effects of compositional changes on reactivity continuum and decomposition kinetics of lake dissolved organic matter. Journal of Geophysical Research: Biogeosciences 121:1733-1746.

Murphy, K. R., C. A. Stedmon, D. Graeber, and R. Bro. 2013. Fluorescence spectroscopy and multi-way techniques. PARAFAC. Analytical Methods 5:6557-6566.

Murphy, K. R., C. A. Stedmon, P. Wenig, and R. Bro. 2014. OpenFluor-An online spectral library of auto-fluorescence by organic compounds in the environment. Analytical Methods 6:658-661.
Osburn, C. L., T. J. Boyd, M. T. Montgomery, T. S. Bianchi, R. B. Coffin, and H. W. Paerl. 2016. Optical proxies for terrestrial dissolved organic matter in estuaries and coastal waters. Frontiers in Marine Science 2:127.

Osburn, C. L., C. R. Widgahl, S. C. Friz, and J. E. Saros. 2011. Dissolved organic matter composition and photoreactivity in prairie lakes of the US Great Plains. Limnology and Oceanography 56:2371-2390.

Parlanti, E., K. Wörz, L. Geoffroy, and M. Lamotte. 2000. Dissolved organic matter fluorescence spectroscopy as a tool to estimate biological activity in a coastal zone submitted to anthropogenic inputs. Organic Geochemistry 31:1765-1781.

Parr, T. B., C. S. Cronan, T. Ohno, S. E. G. Findlay, S. M. C. Smith, and K. S. Simon. 2015. Urbanization changes the composition and bioavailability of dissolved organic matter in headwater streams. Limnology and Oceanography 60:885-900.

Plummer, M. 2013. rjags: Bayesian graphical models using MCMC. (Available from: https://CRAN.R-project.org/package $=$ rjags)

Pollard, P. C. 2013. In situ rapid measures of total respiration rate capture the super labile DOC bacterial substrates of freshwater. Limnology and Oceanography: Methods 11:584-593.

Qualls, R. G., and B. L. Haines. 1992. Biodegradability of dissolved organic matter in forest throughfall, soil solution, and stream water. Soil Science Society of America Journal 56:578-586.

Revelle, W. R. 2017. psych: Procedures for personality and psychological research. Northwestern University, Evanston, Illinois. (Available from: https://CRAN.R-project.org/package = psych)

Risse-Buhl, U., N. Trefzger, A. G. Seifert, W. Schönborn, G. Gleixner, and K. Küsel. 2012. Tracking the autochthonous carbon transfer in stream biofilm food webs. FEMS Microbiology Ecology 79:118-131.

Rouder, J. N., R. D. Morey, P. L. Speckman, and J. M. Province. 2012. Default Bayes factors for ANOVA designs. Journal of Mathematical Psychology 56:356-374.

Seybold, E., and B. McGlynn. 2018. Hydrologic and biogeochemical drivers of dissolved organic carbon and nitrate uptake in a headwater stream network. Biogeochemistry 138:23-48.

Shutova, Y., A. Baker, J. Bridgeman, and R. K. Henderson. 2014. Spectroscopic characterisation of dissolved organic matter changes in drinking water treatment: From PARAFAC analysis to online monitoring wavelengths. Water Research 54:159169.

Skully, N. M., N. Maie, S. K. Dailey, J. N. Boyer, R. D. Jones, and R. Jaffe. 2004. Early diagenesis of plant-derived dissolved organic matter along a wetland, mangrove, estuary ecotone. Limnology and Oceonagraphy 49:1667-1678.

Stedmon, C. A., and S. Markager. 2005. Tracing the production and degradation of autochthonous fractions of dissolved organic matter by fluorescence analysis. Limnology and Oceanography 50:1415-1426.

Steen, A. D., L. N. M. Quigley, and A. Buchan. 2016. Evidence for the priming effect in a planktonic estuarine microbial community. Frontiers in Marine Science 3:6.

Steinman, A. D., G. A. Lamberti, and P. R. Leavitt. 2007. Biomass and pigments of benthic algae. Pages 357-379 in F. R. Hauer and G. A. Lamberti (editors). Methods in stream ecology. Elsevier, Amsterdam, The Netherlands. 
Textor, S. R., F. Guillemette, P. A. Zito, and R. G. M. Spencer. 2018. An assessment of dissolved organic carbon biodegradability and priming in blackwater systems. Journal of Geophysical Research: Biogeosciences 123:2998-3015.

Thomas, S. A., T. V. Royer, E. B. Snyder, and J. C. Davis. 2005. Organic carbon spiraling in an Idaho river. Aquatic Sciences 67:424-433.

Tranvik, L. J., and S. Bertilsson. 2001. Contrasting effects of solar UV radiation on dissolved organic sources for bacterial growth. Ecology Letters 4:458-463.

Trevathan-Tackett, S. M., A. C. G. Thomson, P. J. Ralph, and P. I. Macreadie. 2018. Fresh carbon inputs to seagrass sediments induce variable microbial priming responses. Science of the Total Environment 621:663-669.

Vähätalo, A. V., and R. G. Wetzel. 2008. Long-term photochemical and microbial decomposition of wetland-derived dissolved organic matter with alteration of ${ }^{13} \mathrm{C}:{ }^{12} \mathrm{C}$ mass ratio. Limnology and Oceanography 53:1387-1392.

van Nugteren, P., L. Moodley, G. J. Brummer, C. H. Heip, P. M. Herman, and J. J. Middelburg. 2009. Seafloor ecosystem functioning: The importance of organic matter priming. Marine Biology 156:2277-2287.

Wagner, K., M. M. Bengtsson, R. H. Findlay, T. J. Battin, and A. J. Ulseth. 2017. High light intensity mediates a shift from allochthonous to autochthonous carbon use in phototrophic stream biofilms. Journal of Geophysical Research: Biogeosciences 122:1806-1820.

Ward, N. D., T. S. Bianchi, H. O. Sawakuchi, W. Gagne-Maynard, A. C. Cunha, D. C. Brito, V. Neu, A. Matos Valerio, R. Silva, and A. V. Krusche. 2016. The reactivity of plant-derived organic matter and the potential importance of priming effects along the lower Amazon River. Journal of Geophysical Research: Biogeosciences 121:1522-1539.

Webster, J. R., and J. L. Meyer. 1997. Organic matter budgets for streams: A synthesis. Journal of the North American Benthological Society 16:3-13.

Webster, J. R., and H. M. Valett. 2007. Solute dynamics. Pages 169-185 in F. R. Hauer and G. A. Lamberti (editors). Methods in stream ecology. Elsevier, Amsterdam, The Netherlands.

Weishaar, J. L., G. R. Aiken, B. A. Bergamaschi, M. S. Fram, R. Fujii, and K. Mopper. 2003. Evaluation of specific ultraviolet absorbance as an indicator of the chemical composition and reactivity of dissolved organic carbon. Environmental Science \& Technology 37:4702-4708.

Wetzel, R. G. 2001. Limnology: Lake and river ecosystems. $3^{\text {rd }}$ edition. Academic Press, London, UK.

Wiegner, T. N., and S. P. Seitzinger. 2001. Photochemical and microbial degradation of external dissolved organic matter inputs to rivers. Aquatic Microbial Ecology 24:27-40.

Yamashita, Y., R. Jaffé, N. Maie, and E. Tanoue. 2008. Assessing the dynamics of dissolved organic matter (DOM) in coastal environments by excitation emission matrix fluorescence and parallel factor analysis (EEM-PARAFAC). Limnology and Oceanography 53:1900-1908.

Yamashita, Y., and E. Tanoue. 2003. Chemical characterization of protein-like fluorophores in DOM in relation to aromatic amino acids. Marine Chemistry 82:255-271.

Zsolnay, A., E. Baigar, M. Jimenez, B. Steinweg, and F. Saccomandi. 1999. Differentiating with fluorescence spectroscopy the sources of dissolved organic matter in soils subjected to drying. Chemosphere 38:45-50. 